REVISTA DE DERECHO UNED, núm. 5, 2009

\title{
SELECCIÓN, EVALUACIÓN Y ACREDITACIÓN DEL PROFESORADO ANTE EL ESPACIO EUROPEO DE EDUCACIÓN SUPERIOR
}

\author{
M. ${ }^{a}$ Fernanda Moretón SAnZ*
}

Resumen: Hasta 2001 y desde 1983 el profesorado universitario estaba compuesto por dos grandes grupos, «catalogados» en función de su adscripción a la condición funcionarial o a la singular categoría del "contratado-administrativo" tertius genus que hacía de este sector un singular híbrido desprovisto tanto de representación sindical como del amparo de acuerdos y mesas de negociación de la función pública. En estas líneas nos centraremos en el recorrido del profesorado contratado que emprende su carrera académica desde alguna de las categorías que actualmente no requieren de evaluación previa por Agencias externas (Becas, Ayudantías, Asociados parciales) hasta que obtiene la evaluación que permite consolidar su empleo mediante una selección pública previa o, en su caso,

* Profesora contratada doctora del Departamento de Derecho civil de la Universidad Nacional de Educación a Distancia (UNED). Profesora tutora del Centro Asociado de Guadalajara (España) fmoreton@der.uned.es Representante Claustral del Profesorado contratado UNED. Este trabajo constituye el texto íntegro de la ponencia presentada a la Sesión 2 sobre el Diseño de tareas y sistema tutorial, del Congreso Internacional sobre Investigación e Innovación de la docencia universitaria en el EEES (InnovaDOC), organizado por el Departamento de Didáctica, Organización Escolar y Didácticas Especiales/Departamento de Derecho civil de la UNED y celebrado en Madrid, del 18 al 21 de junio de 2009 UNED, ocupando la Presidencia del Congreso el Prof. Antonio MEDINA REVILLA, Catedrático de la Facultad de Educación y la Secretaría el Prof. Colaborador Doctor de Derecho Civil Francisco Javier JIMÉNEZ MÚÑOZ. Adicionalmente quiero dejar testimonio de mi gratitud y agradecimiento a los miembros del Comité Científico y Organizador y muy especialmente a la Profesora $\mathrm{D}^{\mathrm{a}} \mathrm{M}^{\mathrm{a}}$ Fátima YÁÑEZ VIVERO, Contratada Doctora del Departamento de Derecho Civil, quien tuvo la deferencia y generosidad de defender la ponencia ante la imposibilidad de la autora de estas líneas de hacerlo personalmente. 
se resuelve favorablemente su acreditación, requisito previo también para que, en su caso, si se convoca y supera de el concurso de acceso correspondiente logrará pasar a un cuerpo docente universitario y con ello adquirirá la condición de personal estatutario o funcionario. Y en todo este entramado contractual y funcionarial, hemos de detenernos en la figura específica de la UNED, la del «Profesorado tutor» que al día de hoy sigue ostentando la condición de Becario, ajeno al Estatuto específico de este sector, y es quien hasta ahora se ocupaba de ventilar y materializar la presencialidad con los estudiantes UNED. Veremos ahora cómo se cohonesta la renovación metodológica que reclama el EEES con el «encargo tutorial» aprobado recientemente por los órganos de gobierno de nuestra Universidad.

Palabras clave: Legislación universitaria. Régimen jurídico del Profesorado. Universidad. Espacio Europeo de Educación Superior.

Abstract: Up to 2001 and from 1983 the professor was compound for two big groups, "classified» in function from his adscription to the functionary or the singular category of the «administrative» tertius genus that he made of this sector a singular hybrid devoid point of union representation as of the help of agreements and tables of negotiation of the public function. In these lines be centred in the hired faculty's journey that it undertakes their academic trajectory from some of the categories that at the moment don't require of previous evaluation for external Agencies until obtains the evaluation that allows to consolidate their employment by means of a previous public selection or, in their case, he/she is solved to verify favorably, requisite also so that, in their case, if it is summoned and it overcomes of the competition of corresponding access it will be able to pass to a category university and with will acquire it the condition of personal statutory or official. And in this whole contractual and functionary we must to detain in the specific figure of the UNED, that of the "tutor» that continues showing Scholarship holder's condition to today's day, unaware to the specific Statute of this sector, and it is who up to now was in charge of to ventilate presence with the students UNED. We will see now how the cohesion of the methodological renovation that the EEES with the «responsibility tutelage» approved recently by the organs of government of our University.

Key words: Unversitary legislation. Regulation of the professor. University. European Higher Education Area (EHEA).

Sumario: I. Planteamiento.-II. consideraciones previas sobre las incertidumbres jurídicas en materia universitaria.-I.1. El presente: la 
dispersión normativa en materia de profesorado universitario.-I.2. El futuro de la actividad académica: el Estatuto del Personal Docente e Investigador y la función tutorial en la UNED y la Disposición adicional primera.-III. Metodología, tutoría docente y función tutorial: el «encargo tutorial» en la UNED.-III.1. La reforma de las metodologías educativas y la herramientas.-III.2. La renovación metodológica ante el EEES: modalidades de enseñanza según la comisión para la renovación.-III.3. La tutoría docente: modalidad organizativa de la enseñanza universitaria presencial en el EEES.-III.4. La función tutorial de la UNED como actividad típica: diferencias con la tutoría como modalidad organizativa en las presenciales.-III.5. La relación con el profesorado tutor como obligación del profesorado de la sede central según el futuro Estatuto del PDI y el «encargo tutorial».-IV. Departamentos y unidades ámbitos y áreas de conocimiento: la función docente.-IV.1. Cuestiones sobre la reforma de la estructura de los Departamentos: de órganos a unidades administrativas.-IV.2. De las asignaturas y áreas de conocimiento en el EEES: las cinco ramas y las materias de cada rama.-IV.3. De las áreas de conocimiento a los «ámbitos» de conocimiento.-IV.3.1. Las áreas de conocimiento en la Ley de Reforma Universitaria de 1983 y el Tribunal Constitucional: comisiones y catálogos.-IV.3.2. La noción área de conocimiento: su incorporación expresa sin carácter orgánico según la Ley Orgánica 6/2001, de 21 de diciembre, de Universidades.-IV.3.3. Aparición de los «ámbitos» para sustituir a las «áreas» de conocimiento en el debate parlamentario.-IV.4. La función docente: los límites basados en la organización de la docencia.-V. El sistema plural de acceso a la docencia universitaria.-V.1. Planteamiento: la convivencia de hasta tres sistemas de acceso a la docencia universitaria.-V.2. El nuevo sistema de acreditaciones por rama de conocimiento.-V.2.1. La AENCA como fundación estatal.-V.2.2. Acreditación por ramas: la certificación nacional independientemente de la rama.-V.2.3. La cuantificación de méritos para la acreditación nacional para el acceso a los cuerpos docentes: análisis particular del caso del cuerpo funcionarial de titulares y catedráticos de Universidad.-V.2.4. Concursos de acceso: la capacitación de los miembros de las comisiones de selección.-V.3. Profesorado contratado: el sistema y criterios de evaluación en la ANECA.-V.4. Notas sobre el derecho a la evaluación y reconocimiento de sexenios de investigación del profesorado contratado: la UNED y el convenio de colaboración con la CNEAI.-VI. Reflexiones conclusivas. 


\section{PLANTEAMIENTO}

Si nos situamos en la época constitucional española, sabido es que hasta 2001 y desde 1983 el profesorado universitario estaba compuesto por dos grandes grupos, «catalogados» en función de su adscripción a la condición funcionarial o a la singular categoría del "contratado-administrativo" tertius genus que hacía de este sector un singular híbrido desprovisto tanto de representación sindical como del amparo de acuerdos y mesas de negociación de la función pública ${ }^{1}$.

En estas líneas nos centraremos en el recorrido del profesorado contratado que emprende su carrera académica desde alguna de las categorías que actualmente no requieren de evaluación previa por Agencias externas (Becas, Ayudantías, Asociados parciales) hasta que obtiene o bien la evaluación que permite consolidar su empleo mediante una selección pública previa o, en su caso, se resuelve favorablemente su acreditación, requisito previo también para que, en su caso, si se convoca y supera de el concurso de acceso correspondiente logrará pasar a un cuerpo docente universitario y con ello adquirirá (previa la superación de otros requisitos de los que ahora hacemos gracia) la condición de personal estatutario o funcionario.

En este sentido y por lo que a la desaparición de aquella figura del contratado administrativo se refiere, el factor normativo que inicia la laboralización del profesorado no funcionario es la Ley Orgánica 6/2001, de 21 de diciembre, de Universidades. Adicionalmente a la renovación de buena parte del régimen jurídico de las Universidades, se ha de tener en cuenta que esta LOU convierte en objetivo irrenunciable la mejora de la calidad del sistema universitaria, profundizándose con ella en la denominada «cultura de la evaluación» a través de la Agencia Nacional de Evaluación de la Calidad y Acreditación y estableciéndose «mecanismos para el fomento de la excelencia: mejorar la calidad de la docencia y la investigación, a través de un nuevo sistema objetivo y transparente, que garantice el mérito y la capacidad en la selección y el acceso del profesorado».

Propósito este de la calidad y de la «exigencia de rendir cuentas sobre el cumplimiento de sus funciones», que se verá ratificado en la

1 Vid., el cd del Congreso citado donde se incluyen los puntos I, II y VI, Madrid, 2009, págs. 20 a 26 (ISBN 978-84-8322.634.6). 
reforma operada por la Ley Orgánica 4/2007, de 12 de abril, que modifica el modelo de selección del profesorado funcionario «incorporando un modelo de acreditación que permita que las universidades seleccionar a su profesorado entre los previamente acreditados. Este sistema incorpora para el conjunto de la comunidad académica un mayor rigor en la acreditación y una mayor flexibilidad para las universidades en la selección de su personal».

Por tanto, en estas líneas revisaremos tanto el sistema como los criterios para la evaluación de las figuras específicas de Ayudante Doctor o Contratado Doctor, destacando que la diferencia básica es que, una vez superado el concurso de la plaza de profesorado en régimen laboral, la primera se caracteriza por su duración temporal toda vez que tal y como se prevé la LOLOU en su artículo 50 «la duración del contrato no podrá ser inferior a un año ni superior a cinco, pudiendo prorrogarse o renovarse si se hubiera concertado por duración inferior a la máxima, siempre que la duración total no exceda de los indicados cinco años. En cualquier caso, el tiempo total de duración conjunta entre esta figura contractual y la prevista en el artículo anterior [ayudante], en la misma o distinta universidad, no podrá exceder de ocho años. Las situaciones de incapacidad temporal, maternidad y adopción o acogimiento durante el período de duración el contrato, interrumpirán su cómputo».

Por su parte, la figura del profesorado contratado doctor se caracteriza ahora tanto por su "plena capacidad docente e investigadora" (art. 52) como por la duración de su contrato "que será de carácter indefinido y con dedicación a tiempo completo».

En cuanto al sistema actualmente imperante para la adquisición de la condición funcionarial hace que se haya abandonado el de habilitación previsto en la LOU de de 2001 por el acreditación, elegido por la LOLOU de 2007, con la particularidad en este último supuesto de la distinta formulación que de los concursos de acceso se ha hecho en cada Universidad. Destacaremos tanto los méritos necesarios para adquirir la acreditación previa, como las pruebas que cada Universidad ha dispuesto para sus acreditados.

$Y$ en todo este entramado contractual y funcionarial, hemos de detenernos en la figura específica de la UNED, la del «Profesorado tutor" que al día de hoy sigue ostentando la condición de Becario, ajeno al Estatuto específico de este sector, y es quien hasta ahora se ocupaba de ventilar y materializar la presencialidad con los estu- 
diantes UNED. Veremos ahora cómo se cohonesta la renovación metodológica que reclama el EEES con el "encargo tutorial» aprobado recientemente por los órganos de gobierno de nuestra Universidad.

Por tanto y con las premisas anteriores, este trabajo examinará las consecuencias directas de la reforma jurídica universitaria y del denominado Espacio Europeo de Educación Superior, en los derechos y deberes del profesorado universitario, teniendo en cuenta que está en fase de negociación el que será el «Estatuto del Personal Docente e Investigador».

II. CONSIDERACIONES PREVIAS SOBRE LAS

INCERTIDUMBRES JURÍDICAS EN MATERIA

DE POLÍTICA UNIVERSITARIA ESPAÑOLA

\section{II.1. El presente: la dispersión normativa en materia de profesorado universitario}

Téngase en cuenta que la pluralidad del ordenamiento jurídico aplicable al profesorado universitario se caracteriza por su dispersión, a la que se añade las competencias en la materia asumidas por las Comunidades Autónomas y los correspondientes Estatutos de cada Universidad. En este sentido y pese a todo, sigue vigente, en lo que no contravenga a la LOU de 2001 ni a la LOLOU de 2007, el Real Decreto 898/1985, de 30 de abril, sobre régimen del profesorado universitario, dictado en desarrollo de la Ley Orgánica 11/1983, de 25 de agosto, de Reforma Universitaria, a lo que se añade tanto al profesorado que ostente la condición funcionarial como el laboral, la Ley 7/2007, de 12 de abril, del Estatuto Básico del Empleado Público y a aquéllos el Real Decreto Legislativo 1/1995, de 24 de marzo, por el que se aprueba el texto refundido de la Ley del Estatuto de los Trabajadores.

Adicionalmente se ha de tener en cuenta también el Real Decreto 1.312/2007, de 5 de octubre, por el que se establece la acreditación nacional para el acceso a los cuerpos docentes universitarios - y en los procedimientos aún no resueltos, el Real Decreto $774 / 2002$, de 26 de julio, que regula el sistema ahora derogado de habilitación nacional para el acceso a Cuerpos de Funcionarios docentes universitarios y el régimen de los concursos de accesos respectivos- así como el Real Decreto 1.313/2007, de 5 de octubre, por el que se regula el régimen de los concursos de acceso del profe- 
sorado acreditado y los respectivos desarrollos hechos por cada Universidad sea mediante la vía transitoria del acuerdo del Consejo de Gobierno en tanto no se aborde la preceptiva reforma de los Estatutos, o en los casos de las Universidades que han sido capaces de hacerlo, sus previsiones de desarrollo se han incorporado a dichos nuevos Estatutos adaptados a la LOLOU.

En particular y en cuanto a la UNED, se ha de añadir el contenido del Real Decreto 50/2004, de 19 de enero, por el que se regula el régimen del profesorado contratado de la Universidad Nacional de Educación a Distancia, que advierte que sus relaciones se regularán por el Derecho laboral y los convenios que sean negocia$\mathbf{d o s}^{2}$. En este sentido se ha de tener en cuenta que la circunstancia de la «laboralización» del profesorado contratado, que se remonta a la LOU de 2001 ha traído inestimables consecuencias tanto en la negociación como en el fortalecimiento de la representación sindical de este sector. En particular en la UNED, contamos con el Comité de Empresa del Personal Docente e Investigador Laboral (CE-PDIL) web http://portal.uned.es/portal/page?_pageid=93,731063\&_ $\mathrm{dad}=$ portal\&_schema=PORTAL ${ }^{3}$.

También se añade el Real Decreto 1.393/2007 de 29 de octubre, por el que se establece la ordenación de las enseñanzas universitarias oficiales, ya que entre otras cuestiones, su Anexo I sobre Memoria para la solicitud de verificación de títulos oficiales, es la que incluye la mención sobre el área de conocimiento y en Anexo II Las materias básicas por rama de conocimiento.

2 El primer Convenio Colectivo del Personal docente e investigador laboral de la UNED, es del pasado 25 de marzo de 2009 y en tanto no sea publicado en el Boletín de la CAM (al resultar este el competente por razón del ámbito territorial de aplicación) se puede consultar en la dirección http://portal.uned.es/portal/page?_pageid= 93,731063\&_dad=portal\&_schema=PORTAL

3 Su pág web dice: «El Comité de Empresa del Personal Docente e Investigador Laboral (CE-PDIL) de la UNED es la representación sindical del profesorado contratado laboral y de los investigadores de la Universidad Nacional de Educación a Distancia. Para detallar más, este comité representa a cualquier persona que trabaja en la UNED con alguno de estos contratos laborales: a) asociados a tiempo parcial LOU; b) ayudantes LOU; c) ayudantes doctores; d) colaboradores; e) profesores contratados doctores; f) eméritos, g) visitantes; h) personal investigador laboral en formación; i) investigadores contratados (Ramón y Cajal, Juan de la Cierva, postdoctorales ...); j) contratados por acumulación de tareas y k) contratados por obra y servicio». "La composición del Comité de Empresa PDI Laboral parte de las elecciones sindicales del 29 de junio de 2006». Por su parte, la Junta de Personal Docente e Investigador (JPDI) representa a los profesores de los Cuerpos Docentes Universitarios (Funcionarios) y a los Profesores con contrato administrativo LRU (ayudantes LRU y asociados LRU). 


\section{II.2. El futuro de la actividad académica: el estatuto del personal docente e investigador y la función tutorial en la uned y la disposición adicional primera}

En la inicial propuesta del Borrador del Estatuto del Personal Docente e Investigador de las Universidades españolas, según el texto a 10 de noviembre de $\mathbf{2 0 0 8}$, se concretaba en su primer artículo lo que sería el Objeto y ámbito de aplicación de este futuro Real Decreto: «1. El objeto del presente Real Decreto es el régimen jurídico del personal docente e investigador de las Universidades públicas pertenecientes a los cuerpos docentes universitarios previstos en el artículo 56 de la Ley Orgánica 6/2001, de 21 de diciembre, de Universidades, redactada de conformidad con lo dispuesto en el artículo único de la Ley Orgánica 4/2007, de 12 de abril, por la que se modifica la Ley Orgánica 6/2001, de 21 de diciembre, de Universidades y teniendo en cuenta las disposiciones adicionales primera y segunda de ésta última. 2. El personal docente e investigador contratado previsto en el los artículos 48 a 54 de la Ley orgánica 6/2001, de 21 de diciembre de universidades se regirá también por las disposiciones del presente estatuto que les sean de directa aplicación, sin perjuicio de lo establecido en la Ley 7/2007, de 12 de abril reguladora del estatuto básico del empleado público y de las competencias de las Comunidades Autónomas. 3. En el ámbito del presente Real Decreto, se entiende por actividad académica, el conjunto de funciones que debe cumplir un profesor universitario a lo largo de su carrera académica: actividad docente, actividad investigadora, participación institucional, participación en la gestión universitaria, y actividad de transferencia de conocimiento e innovación».

Adicionalmente y por lo que al Profesorado Universitario que preste sus servicios en la UNED, imputando como obligación específica del de la Sede Central la relación con el Profesorado tutor de los Centros Asociados: Dice así su Disposición adicional primera: Del Personal docente e investigador funcionario la Universidad Nacional de Educación a Distancia: «1. Sin perjuicio de las previsiones establecidas en la disposición adicional segunda de la LOMLOU, de las obligaciones generales establecidas en el presente Real Decreto y en los Estatutos de la Universidad, el personal docente investigador funcionario de la Universidad Nacional de Educación a Distancia, en atención a sus especiales características, estará sujeto al siguiente régimen específico: a). Este personal docente e investigador tiene el deber de desempeñar las tareas docentes e investigadoras y, en particular, participar en la elaboración del material didáctico que la 
Universidad determine como específico de la enseñanza a distancia y adaptado a las tecnologías de la información y la comunicación. b). Deberá, asimismo, atenerse a las directrices y plazos que, en orden al desarrollo de la metodología de enseñanza a distancia y sin menoscabo de su libertad de cátedra, se adopten para la mejor elaboración y adecuación didáctica de dichos materiales. c). Los Estatutos de la Universidad determinarán los criterios de equiparación entre el régimen de dedicación establecido con carácter general para el profesorado funcionario universitario en el presente Real Decreto, y el de dicho personal adscrito a la Universidad Nacional a Distancia, en orden a la asignación de sus tareas docentes e investigadoras, y a la determinación del régimen de sus obligaciones de permanencia, de asistencia a los alumnos, de relación con los profesores tutores y demás actividades propias de la enseñanza a distancia. d). Este personal tiene el derecho y el deber de recibir la formación específica precisa para el desarrollo de la actividad de enseñanza a distancia. e). Este personal tiene la obligación de realizar los desplazamientos que, por exigencia de participación en los tribunales de exámenes y de las obligaciones docentes y académicas inherentes a la enseñanza a distancia, deban efectuar a las unidades territoriales de la Universidad y a los centros asociados. 2. En tanto el Gobierno establezca la regulación específica contemplada en la Disposición Adicional Segunda de la Ley Orgánica de Universidades, los Profesores Tutores de los centros asociados de la UNED se regirán por lo dispuesto en el Estatuto de esta Universidad y en el reglamento de régimen interior del Centro Asociado al que se encuentren vinculados».

Visto el cambio ministerial ${ }^{4}$ y el estado de las negociaciones baste, de momento, referirse a estas escuetas menciones sobre la UNED en las que, por cierto, se imponen obligaciones sobre la elaboración de materiales docentes sin que se sepa si el Régimen de Propiedad Intelectual quedará afectado por las creaciones realizadas en el ámbito de un contrato o relación funcionarial ${ }^{5}$.

${ }^{4}$ El Ministerio de Ciencia e Innovación «pierde» las competencias en materia de Universidades que pasan, de nuevo al Ministerio de Educación (vid., Real Decreto $542 / 2009$, de 7 de abril, por el que se reestructuran los departamentos ministeriales).

5 En la materia vid., el tenor del artículo 51 de la Ley de Propiedad Intelectual: «1. Transmisión de los derechos del autor asalariado 1. La transmisión al empresario de los derechos de explotación de la obra creada en virtud de una relación laboral se regirá por lo pactado en el contrato, debiendo éste realizarse por escrito. 2. A falta de pacto escrito, se presumirá que los derechos de explotación han sido cedidos en exclusiva y con el alcance necesario para el ejercicio de la actividad habitual del empresario en el momento de la entrega de la obra realizada en virtud de dicha relación 


\section{METODOLOGÍA, TUTORÍA DOCENTE Y FUNCIÓN TUTORIAL: EL «ENCARGO TUTORIAL»EN LA UNED}

\section{III.1. La reforma de las metodologías educativas y la herramientas}

En otros estudios hemos analizado si mediante el uso de herramienta, como pueda ser la herramienta $\operatorname{AVIP}^{6}$ se altera el régimen y competencias del profesorado-tutor de la UNED sin la

laboral. 3. En ningún caso podrá el empresario utilizar la obra o disponer de ella para un sentido o fines diferentes de los que se derivan de lo establecido en los dos apartados anteriores. 4. Las demás disposiciones de esta Ley serán, en lo pertinente, de aplicación a estas transmisiones, siempre que así se derive de la finalidad y objeto del contrato. 5. La titularidad de los derechos sobre un programa de ordenador creado por un trabajador asalariado en el ejercicio de sus funciones o siguiendo las instrucciones de su empresario se regirá por lo previsto en el apartado 4 del artículo 97 de esta Ley« (Real Decreto Legislativo 1/1996, de 12 de abril, por el que se aprueba el Texto Refundido de la Ley de Propiedad Intelectual; para su comentario RODRÍGUEZ TAPIA, Comentarios a la Ley de Propiedad Intelectual, BERCOVITZ RODRÍGUEZ-CANO (Coord.), Madrid, 2007, 3. a ed., págs. 838 a 850; RODRÍGUEZ TAPIA, Comentarios a la Ley de Propiedad Intelectual, RODRÍGUEZ TAPIA (Dir.), Madrid, 2007, págs. 381 a 385).

6 Para ello me remito a la comunicación presentada al IV Foro sobre Evaluación de la Calidad de Educación Superior y de la Investigación, que llevaba por título «Las modalidades de enseñanza y la función tutorial en la UNED: planes estratégicos, herramientas docentes audiovisuales y renovación metodológica ante el EEES», cuyo resumen y vínculo al texto pueden consultarse en el libro electrónico con ISBN 978-84690-8321-5. Y a la comunicación «La herramienta AVIP y la pizarra virtual ante la tutorización de las enseñanzas jurídicas en la UNED», II Congreso de Innovación Docente en Ciencias Jurídicas: hacia el EEES. En principio, la herramienta Audiovisual IP (AVIP) - así como la Pizarra Virtual-, es un instrumento que, aplicado especialmente a la función tutorial presencial, tiene la intención de maximizar sus resultados para que, a su vez, dichas tutorías presenciales sean utilizadas por aquellos y aquellas estudiantes que no puedan frecuentar las aulas de los Centros asociados de la UNED. Descrita en el Plan estratégico como «herramienta docente Audiovisual IP para la Tutoría Temática a Distancia (TTD)» tiene como objetivo específico la creación de «una plataforma docente que integre tecnología síncrona aprovechando los avances arquitectónicos de los sistemas informáticos de la UNED con el fin de que la oferta docente de los Centros llegue a partes donde hoy no lo hace, así como una utilización más amplia de las sesiones y materiales de apoyo generados por los propios Centros» (VICERRECTORADO DE CENTROS ASOCIADOS. UNED, «Documento: Desarrollo de una Estructura Integrada de los Centros Asociados de la UNED», 2006-2007) de modo su contenido debe ser examinado tanto a la luz del Documento donde se pretende modificar la estructura integrada de los Centros de la UNED, como del propio EEES. En puridad se trata de que la tutoría presencial que imparta un profesor o profesora tutora en uno de los Centros asociados de la UNED sea retransmitida en tiempo real a otra sede geográfica distinta para que los estudiantes que acudan a este último lugar, puedan participar activamente en dicha clase. Adicionalmente dichos contenidos serían grabados y «colgados» en las páginas virtuales de cada asignatura 
preceptiva reforma del régimen jurídico. Téngase en cuenta que las casi seis mil personas que prestan sus servicios como tutores y tutoras, desempeñan estas funciones tutoriales al amparo de la calificación técnica de «becarios» fijos discontinuos ${ }^{7}$ sea con «venia» o sin ella.

A mayor abundamiento, también quiere destacarse que la tutoría en el marco genérico del EEES, no puede confundirse con las funciones jurídicamente atribuidas $\mathrm{y}$ asumidas por el profesorado-tutor de la UNED. De modo que, la coincidencia terminológica no implica la identidad de regímenes, ni de funciones, retribuciones, exigencias, formación y reconocimiento contractual que presenta el profesorado sometido, unos, al ordenamiento laboral o a la función pública a tiempo parcial o completo, y los otros a la condición de becarios con un régimen de dedicación nominalmente no superior a las setenta y cinco horas anuales ${ }^{8}$.

\section{III.2. La renovación metodológica ante el eees: modalidades de enseñanza según la comisión para la renovación}

Entre las novedades que se han ido desarrollado en los últimos tres años en la UNED, uno de los propósitos de la denominada herramienta AVIP puede ser examinado tanto desde la perspectiva tradicional del contenido tutorial, como desde las apreciaciones formuladas por la Comisión para la Renovación de las Metodologías Educativas en la Universidad, en tanto declara que «el diagnóstico de

(o/y en el repositorio institucional) para que, en su caso, otros estudiantes pudiesen disfrutar en diferido de dichas explicaciones (Sobre la didáctica crítica y el método educativo tecnológico, vid., SANTAMARÍA LANCHO, «UNED-Aula Virtual: una herramienta para la creación de aulas virtuales para la enseñanza a distancia», Comunicación presentada al I Congreso Internacional sobre Comunicación y Educación. Multimedia y Educación en un Mundo globalizado, del 20 al 23 de mayo de 1998, Sao Paulo, Brasil).

7 Entre los principales estudios sobre la metodología a distancia y específicamente de la UNED se encuentran los de GARCÍA AREITIO, así vid., entre otros, $L a$ Educación a distancia y la UNED, Madrid, 1996; "Instituto Universitario de Educación a Distancia (IUED)», 25 años de la UNED, Madrid, 1999, págs. 535 a 544.

8 Otros aspectos relativos a los derechos de autor y propiedad intelectual, la autorización para la publicación en el «repositorio»e, incluso, el ejercicio del derecho de cátedra en contradicción con el programa del responsable de la asignatura, merecen como mínimo ser aquí planteados, si bien se reserva su estudio para otros trabajos posteriores. Otro apunte se refiere al examen e intervención por parte de terceros de los contenidos emitidos y grabados, y el autocontrol y autoexigencia que puede implicar para quien la imparta, la circunstancia de la grabación. 
la situación actual podría sintetizarse afirmando que la reforma de las metodologías educativas se percibe como un proceso que es imprescindible abordar para una actualización de la oferta formativa de las universidades españolas, y que de hecho está ya de alguna forma en marcha, lo que no es óbice para que el mismo concite todavía no pocas incertidumbres. El proceso de construcción del Espacio Europeo de Educación Superior (EEES) se percibe como la oportunidad perfecta para impulsar una reforma que no debe quedarse en una mera reconversión de la estructura y contenidos de los estudios, sino que debe alcanzar al meollo de la actividad universitaria, que radica en la interacción profesores-estudiantes para la generación de aprendizaje (...) La lección magistral sigue siendo la práctica pedagógica dominante en los centros universitarios españoles, aunque cada vez se acompaña más de la realización de ejercicios, la resolución de problemas y la discusión de casos prácticos. (...) La tutoría profesor-estudiante orientada a complementar las clases y el propio trabajo de los alumnos, se considera otra práctica que es preciso potenciar. También las tecnologías informáticas están destinadas a seguir jugando un papel fundamental en la renovación metodológica. La adecuación al futuro EEES requiere abordar un proceso interuniversitario, institucional y estructurado que contemple sucesivas fases (...). Para las universidades, la mejora de la práctica pedagógica pasaría fundamentalmente por incidir en la formación, la evaluación y la incentivación. No obstante, hay práctica unanimidad al señalar que si sólo se atiende a la formación y no se buscan motivaciones e incentivos, no se podrá operar el cambio de actitud del profesorado - piedra angular del cambio- que le lleve a mejorar su formación y su práctica pedagógica» ${ }^{9}$.

En este sentido, también se ha dicho que «uno de los objetivos prioritarios del proceso de convergencia dentro del EEES es que el diseño de los planes de estudio y de las programaciones docentes se lleven a cabo tomando como referencia el aprendizaje del alumno. De ahí que en la elaboración de un plan, además de delimitar los contenidos del programa formativo, deberemos precisar los procedimientos que vamos a utilizar en el desarrollo de los procesos de enseñanza-aprendizaje con el fin de promover el cambio metodológico de una enseñanza centrada sobre la actividad

9 Comisión para la Renovación de las Metodologías Educativas en la Universidad. MEC (Consejo de Universidades), Propuestas para la Renovación de las Metodologías Educativas en la Universidad, Madrid, 2006, pág. 7. 
del profesor a otra orientada hacia el aprendizaje del alumno. Ello implica que una vez establecidas las competencias que debe adquirir el alumno vinculadas a una Titulación diseñemos las actividades y experiencias que debe realizar para alcanzar las mismas como resultados de su proceso de aprendizaje. El diseño de un plan no se puede limitar a repartir materias y créditos sino que debe precisar los métodos de enseñanza que permiten que un estudiante medio pueda conseguir los aprendizajes propuestos; es decir, concretar las modalidades y metodologías de trabajo del profesor y el alumno que se consideran adecuadas en función de los objetivos que pretendemos ${ }^{10}$.

\section{III.3. La tutoría docente: modalidad organizativa de la enseñanza universitaria presencial en el EEES}

De modo que en el futuro EEES «la tutoría puede entenderse como una modalidad organizativa de la enseñanza universitaria en la que se establece una relación personalizada de ayuda en el proceso formativo entre un facilitador o tutor, habitualmente un profesor, y uno o varios estudiantes. El tutor más que «enseñar» atiende, facilita y orienta al estudiante en su proceso formativo, pudiendo ser objeto de atención cualquiera de las facetas o dimensiones que inciden en el mismo (aspectos académicos, actitudinales, personales, sociales...). Desde una perspectiva puramente académica, encontramos dos tipos básicos de organización de las tutorías: como estrategia didáctica y como orientación de la formación académica integral del estudiante. La tutoría como estrategia didáctica centrada en el proceso de enseñanza aprendizaje consiste en el establecimiento de una relación entre el profesor-tutor y el estudiante, ya sea individual o grupalmente, con el fin de facilitarle el aprendizaje en un ámbito disciplinar concreto, normalmente la materia en la que desarrolla el profesor-tutor su docencia. Una forma limitada de entender la tutoría es contemplarla como auxiliar y soporte de la docencia ordinaria de la clase. (...) Pero el potencial de la tutoría es mucho mayor cuando en el conjunto de un programa formativo se concibe como una modalidad o estrategia de enseñanza planificada inicialmente para el desarrollo de determinadas competencias por parte de los estudiantes (selección de fuentes, comunicación, elaboración y

10 DE MIGUEL DÍAZ (Dir.), Modalidades de enseñanzas centradas en el desarrollo de competencias. Orientaciones para promover el cambio metodológico en EEES, MECUniversidad de Oviedo, Oviedo, 2006, pág. 13. 
presentación de informes...) y en combinación planificada con otras modalidades organizativas (las clases teóricas y prácticas, el trabajo autónomo, el trabajo en grupo...). Adquiere así entidad propia como modalidad de enseñanza, convirtiéndose en elemento central para el seguimiento y supervisión de prácticamente todos los métodos de enseñanza que promueven el aprendizaje autónomo de los estudiantes (aprendizaje basado en problemas, aprendizaje orientado a proyectos, contratos de aprendizaje...). Desde esta perspectiva cada profesor actúa como tutor de su materia para todos los estudiantes que la cursan. El profesor-tutor también deberá estar dispuesto a atender a los estudiantes en problemas de índole académico-administrativo, personal o social, en cuanto afecten directamente a su desarrollo académico, pero sin olvidar que el profesor no es un especialista de la orientación. Con la tutoría docente, tal como podríamos etiquetar a esta fórmula de tutoría, pretendemos en todo caso optimizar el proceso de aprendizaje del estudiante en un ámbito disciplinar concreto. En la tutoría como orientación de la formación académica integral del estudiante el profesor-tutor procura facilitar al estudiante su adaptación e integración plena en los estudios que cursa, así como su desarrollo entre los diferentes itinerarios curriculares en vista a su posterior desarrollo profesional. La tutoría acompaña así al estudiante durante toda su trayectoria académica, desde el ingreso al egreso, de forma que el profesor-tutor facilita y estimula al estudiante en su proceso formativo global, asesorándole incluso en las decisiones de elección y especialización curricular propias de la construcción de su perfil profesional individual acorde con sus expectativas, capacidades e intereses. La tutoría orientadora es una modalidad de actividad docente que implica procesos sistematizados, mediante los cuales un profesor es designado como tutor y guía del estudiante en su incorporación y progreso por la universidad a través de una atención personalizada en los asuntos académicos, propiciando su desarrollo integral (...). La tutoría docente y la orientadora no suponen fórmulas antagónicas o diferenciadas, sino complementarias y componentes de dos niveles de intervención: materia y proceso formativo global» ${ }^{11}$.

${ }^{11}$ Comisión para la Renovación de las Metodologías Educativas en la Universidad. MEC (Consejo de Universidades), Propuestas para la Renovación de las Metodologías Educativas en la Universidad, Madrid, 2006, págs. 68 y 69. 


\section{III.4. La función tutorial de la uned como actividad típica: diferencias con la tutoría como modalidad organizativa en las presenciales}

Como es sabido, la Universidad Nacional de Educación a Distancia (UNED) es una Universidad pública de ámbito estatal, creada por Decreto 2.310/1972, de 18 de agosto $^{12}$.

Las sucesivas modificaciones legislativas han tenido en cuenta a nuestra Universidad, así la LO 6/2001, de 21 de diciembre, de Universidades, recoge sus peculiaridades en los siguientes términos: «Disposición adicional segunda. De la Universidad Nacional de Educación a Distancia. 1. La UNED impartirá enseñanza universitaria a distancia en todo el territorio nacional. 2. En atención a sus especiales características, el Gobierno establecerá, sin perjuicio de los principios recogidos en esta Ley, una regulación específica de la UNED, que tendrá en cuenta, en todo caso, el régimen de sus centros asociados y de convenios con las Comunidades Autónomas y otras entidades públicas y privadas, las específicas obligaciones docentes de su profesorado, así como el régimen de los tutores. 3. Dicha regulación, de acuerdo con las previsiones del artículo 7, contemplará la creación de un Centro Superior para la Enseñanza Virtual específicamente dedicado a esta modalidad de enseñanza en los distintos ciclos de los estudios universitarios. Dada la modalidad especial de la enseñanza y la orientación finalista de este centro, tanto su organización, régimen de su personal y procedimientos de gestión, así como su financiación, serán objeto de previsiones particulares respecto del régimen general de la Universidad Nacional de Educación a Distancia».

Teniendo en cuenta estos fundamentos normativos, conviene analizar el marco específico de la función tutorial previsto en los Estatutos de la $\mathrm{UNED}^{13}$, en particular en las prescripciones del artículo octavo por cuanto declara que «la UNED imparte la enseñanza mediante la modalidad de educación a distancia, que se caracteriza por la utilización de una metodología didáctica específica con el empleo conjunto de medios impresos, audiovisuales y de las nuevas tecnologías, así como la asistencia presencial a los alumnos a través de los profesores tutores de los centros asociados y de los diversos sistemas de comunicación entre los profesores y los alumnos».

12 BOE de 9 de septiembre de 1972.

13 Aprobados mediante Real Decreto 426/2005, de 15 de abril. 
Adicionalmente sobre las funciones que pesan sobre el sector del profesorado tutor, establece el artículo 141 lo siguiente: «1. Sin perjuicio de otras funciones que les encomiende la normativa vigente, los profesores tutores ejercen funciones docentes en la UNED, que se concretan básicamente en: a) Orientar al alumno en sus estudios, aclarar y explicar las cuestiones relativas al contenido de las materias cuya tutoría desempeñan, siguiendo las directrices del departamento. b) Informar al profesor responsable de cada asignatura del nivel de preparación de los alumnos. 2. Los profesores tutores realizarán la actividad tutorial presencial en los centros asociados y utilizarán los métodos tecnológicos de comunicación que la UNED adopte en su modelo educativo. 3. De acuerdo con la legislación vigente y a los efectos de concursos, la UNED computará el período de tiempo en que hubieran desarrollado su función docente».

En cuanto al apoyo tutorial en los Centros asociados el artículo 21 determina que «1. Para asegurar la orientación al alumno, los Centros asociados proporcionarán apoyo tutorial, en las titulaciones que tengan adscritas, con los medios más adecuados. 2. Para la mejora del rendimiento académico de los alumnos, la UNED establecerá un sistema de evaluación continua que garantice un adecuado seguimiento del aprendizaje y que facilite la asistencia efectiva de los alumnos a las pruebas de evaluación. 3. El Consejo de Gobierno propondrá al Consejo Social, previo informe del Consejo de Coordinación Universitaria, las normas que regulen el progreso y permanencia en la universidad de los alumnos, en función de las características de los respectivos estudios y del expediente académico del alumno».

A estas prescripciones se añaden las contenidas en el Real Decreto 2005/1986, de 25 de septiembre, sobre Régimen de la función tutorial en los Centros asociados de la $\mathrm{UNED}^{14}$ que declara lo siguiente: "Artículo 1. La UNED desarrolla su actividad docente con la necesaria colaboración de los profesores tutores, quienes forman parte de su comunidad universitaria y participan en los órganos de gobierno de la misma en los términos previstos en sus Estatutos. Artículo. 2. 1. Los profesores tutores de la UNED desempeñan sus funciones en los centros asociados de la misma y de acuerdo con lo contemplado en los artículos 74, 75 y 77 de los Estatutos de la Universidad. 2. Son funciones específicas de los profesores tutores de la UNED: A) Orientar a los alumnos en sus estudios, siguiendo los criterios pe-

14 BOE 30 de septiembre de 1986. 
dagógicos del correspondiente departamento de la universidad nacional de educación a distancia. B) Aclarar y explicar las cuestiones relativas al contenido de las materias cuya tutoría desempeña, resolviendo las dudas de los alumnos en su estudio. C) Participar en la evaluación continua de los alumnos, informando a los profesores de la sede central acerca de su nivel de preparación. D) Colaborar en la labor de los Departamentos a los que estén encomendadas las disciplinas sobre las que ejerza la tutoría, en los términos que establezcan los planes anuales de los mismos. E) Realizar investigación bajo la dirección del departamento correspondiente o colaborar en la que este lleve a cabo, de acuerdo con lo dispuesto en la ley de reforma universitaria y en los estatutos de la UNED» ${ }^{15}$.

De modo que la pretensión de que a los Profesores-tutores UNED les sea de aplicación y asuman como propias las nuevas modalidades de enseñanza que competen y han sido diseñadas para el profesorado universitario presencial, en buena lógica exigirá adaptaciones también de su régimen jurídico. Si algunas de las modalidades organizativas ya eran, ciertamente, compartidas por una parte de los tutoresUNED, otras, por el contrario, difícilmente podrán ser desempeñadas sin un incremento de sus retribuciones o sin un cambio de su régimen de contratación e, incluso, de selección.

Por su parte, la herramienta AVIP — sin duda útil en muchas disciplinas- no evitará que el alumnado de ciencias jurídicas prefiera el soporte humano y profesional que hasta ahora le ha sido proporcionado, así como la experiencia personal «socializar» y materializar el rol de estudiante universitario gracias a la visita y frecuentación de las aulas de su Centro asociado.

Por tanto, se confunde en el Plan estratégico UNED y en la propia herramienta AVIP lo que resulta ser, con ocasión del EEES, una necesaria reforma de las funciones tutoriales proyectadas para la totalidad del profesorado universitario (presencial y no presencial), con lo que es el rol y funciones desempeñadas por el profesor-tutor y tutora en el modelo UNED de enseñanza a distancia.

Repárese que como consecuencia del error señalado, esta transposición del modelo organizativo tutorial del EEES a la función tu-

15 Sobre la función tutorial en la UNED, vid., CASTILLO ARREDONDO y GARCÍA AREITIO, "El tutor y la tutoría en el modelo UNED», GARCÍA AREITIO, La Educación a distancia y la UNED, Madrid, 1996, págs. 165 a 306 y CASTILLO ARREDONDO y GARCÍA AREITIO, "El desarrollo de la acción tutorial», GARCÍA AREITIO, La Educación a distancia y la UNED, Madrid, 1996, págs. 307 a 358. 
torial como actividad típica de la UNED, se convierte en el título con que se altera el contenido de sus atribuciones. Debe recordarse que con los Planes, como instrumento de ordenación, se podrá racionalizar la actividad de los poderes públicos pero no resultan título habilitante, estando además desprovisto del consenso que debe presidir las relaciones entre los operadores universitarios ${ }^{16}$.

Téngase en cuenta que, desde sus inicios, la tutorización-UNED de las enseñanzas jurídicas, no podía convertirse en la ahora denostada clase magistral dada la limitación horaria —en los Centros asociados con mayor matrícula sólo para los grupos más numerosos se proporcionaban en los mejores tiempos hasta 24 horas de tutorización presencial en cada semestre por asignatura-; es dudoso que esta tutorización y sus titulares ostenten plena libertad de cátedra ${ }^{17}$ e imparten un programa con contenidos elaborados por otro; su campo de actuación se suele limitar a doce horas por parcial y asignatura siendo como máximo setenta y cinco horas anuales; y siempre han de seguir las directrices del Departamento tal y como se ha destacado más arriba.

De lo dicho se sigue que deba ser destacada, por escasa, la atención del EEES al modelo de Universidad pública a distancia. Por otra parte y a la vista de lo sorprendente que resulta, que haya bastado la mención a la modalidad organizativa tutorial en la renovación metodológica para que, sin otros trámites y mediante la herramienta AVIP, le haya sido imputada al tutor-UNED. En este sentido, todos los componentes de la comunidad universitaria deberían asumir la adaptación al EEES y en buena lógica, todas las herramientas deberían estar a disposición de la totalidad de sus miembros y no sólo en unos Centros asociados, con la singular consecuencia de tutoresUNED con funciones organizativas EEES gracias a la AVIP y tutoresUNED sin AVIP sin adaptación según dicha lógica al EEES.

\section{III.5. La relación con el profesorado tutor como obligación del profesorado de la sede central según el futuro estatuto del pdi y el "encargo tutorial»}

Como ya se ha dicho y con la advertencia hecha sobre el «especial» estado de negociación de este futuro Real Decreto con ocasión del cambio ministerial, dice así la Disposición adicional primera del

\footnotetext{
16 Sobre los Instrumentos de ordenación, vid., SÁNCHEZ MORÓN, Derecho administrativo. Parte general, Madrid, 2006, 2. ${ }^{\mathrm{a}}$ ed., págs. 624 y sigs.

17 Sobre esta libertad atribuida a todos los docentes, vid., LOZANO CUTANDA, La libertad de cátedra, Madrid, 1995, págs. 108 y sigs.
} 
borrador del Estatuto del Personal Docente e Investigador: «Del Personal docente e investigador funcionario la Universidad Nacional de Educación a Distancia: «1. Sin perjuicio de las previsiones establecidas en la disposición adicional segunda de la LOMLOU, de las obligaciones generales establecidas en el presente Real Decreto y en los Estatutos de la Universidad, el personal docente investigador funcionario de la Universidad Nacional de Educación a Distancia, en atención a sus especiales características, estará sujeto al siguiente régimen específico: a). Este personal docente e investigador tiene el deber de desempeñar las tareas docentes e investigadoras y, a particular, participar en la elaboración del material didáctico que la Universidad determine como específico de la enseñanza a distancia y adaptado a las tecnologías de la información y la comunicación. b). Deberá, asimismo, atenerse a las directrices y plazos que, en orden al desarrollo de la metodología de enseñanza a distancia y sin menoscabo de su libertad de cátedra, se adopten para la mejor elaboración y adecuación didáctica de dichos materiales. c). Los Estatutos de la Universidad determinarán los criterios de equiparación entre el régimen de dedicación establecido con carácter general para el profesorado funcionario universitario en el presente Real Decreto, y el de dicho personal adscrito a la Universidad Nacional a Distancia, en orden a la asignación de sus tareas docentes e investigadoras, y a la determinación del régimen de sus obligaciones de permanencia, de asistencia a los alumnos, de relación con los profesores tutores y demás actividades propias de la enseñanza a distancia. d). Este personal tiene el derecho y el deber de recibir la formación específica precisa para el desarrollo de la actividad de enseñanza a distancia. e). Este personal tiene la obligación de realizar los desplazamientos que, por exigencia de participación en los tribunales de exámenes y de las obligaciones docentes y académicas inherentes a la enseñanza a distancia, deban efectuar a las unidades territoriales de la Universidad y a los centros asociados. 2. En tanto el Gobierno establezca la regulación específica contemplada en la Disposición Adicional Segunda de la Ley Orgánica de Universidades, los Profesores Tutores de los centros asociados de la UNED se regirán por lo dispuesto en el Estatuto de esta Universidad y en el reglamento de régimen interior del Centro Asociado al que se encuentren vinculados».

En el documento sobre la Ordenación de la tutoría en el EEES para potenciar y extender su utilización a todos los estudiantes de la UNED, aprobado en Consejo de Gobierno del 26 de febrero de 2009, se dice en su introducción que en el momento de la elaboración de este do- 
cumento hay más de 6.800 profesores tutores y que únicamente sus servicios alcanzan al veinte por ciento de los estudiantes.

Dice su punto cuarto «Encargo tutorial. Dada la disparidad existente entre los Centros Asociados a la hora de valorar la carga de trabajo de los profesores tutores (en unos Centros Asociados se mide en términos de asignaturas tutorizadas en otros en términos de horas de presencialidad semanal) conviene establecer como medida común el encargo tutorial entendido tal y como se indica a continuación. En la UNED el encargo tutorial, para un profesor tutor que tenga la máxima dedicación permitida por el régimen de incompatibilidades, comprende dos grandes actividades: a) El seguimiento y evaluación continúa de un grupo de 60 a 80 estudiantes. b) La dedicación de una serie de horas a la tutoría presencial mediada o no por tecnologías. El número máximo de horas dedicadas a la tutoría presencial sería de 75 horas por curso académico. 5. Impacto de la evaluación continúa en la carga de trabajo del profesor tutor. Como ya se ha dicho la mayor parte de las actividades propuestas a los estudiantes no requerirán la intervención del profesor tutor pues serán auto-evaluables. La repercusión de la corrección de las actividades evaluables será equivalente a la que tiene actualmente el mantenimiento de Pruebas de Evaluación a Distancia en algunas asignaturas. El impacto en la carga de trabajo solo podrá evaluarse una vez en marcha los nuevos títulos. Será distinto en cada asignatura pues dependerá de las actividades propuestas por el equipo docente y del número de estudiantes que decidan hacerlas. Las experiencias de Redes de Innovación llevadas a cabo en la UNED han demostrado que los equipos necesitan tiempo para introducirla, evaluar sus resultados e ir intensificando su utilización progresivamente. De la misma forma se ha comprobado como, cuando la evaluación continua se oferta con carácter voluntario, los estudiantes también necesitan un tiempo para apreciar sus ventajas y decidirse a participar en ella. Por todo ello, en los momentos iniciales son pocos los estudiantes que optan por esta modalidad. Conforme se vayan incrementando el número de actividades prácticas evaluables y sean más los estudiantes que opten por esta modalidad, deberá valorarse la posibilidad de adaptar la tutoría presencial a los objetivos generales de cada asignatura y en función de los recursos y tiempo disponibles en cada caso. Los Coordinadores Académicos de los Centros y de los Campus valorarán la conveniencia y forma de hacerlo en cada caso» ${ }^{18}$.

18 Publicado en el Bici22/Anexo II, de 26 de marzo de 2009. 
Adicionalmente en este documento se ha introducido una discutida fórmula para la evaluación de la actividad tutorial que dice lo siguiente: «8. La evaluación de la actividad tutorial en el contexto de los sistemas de garantía de calidad de los títulos de Espacio Europeo. El Real Decreto 1393/2007 que regula las enseñanzas universitarias establece la necesidad de que cada título cuente con un sistema de garantía de calidad, que contenga sistemas de revisión y mejora de la actividad docente. Para ello la UNED ha aprobado un procedimiento de evaluación de la actividad docente que incluye, lógicamente, la evaluación de la actividad tutorial. A continuación, se transcribe el apartado 3.5, que le afecta: 3.5. Evaluación de la actividad tutorial. La evaluación de la actividad tutorial será llevada a cabo por los profesores y los equipos docentes, que tendrán en cuenta los informes remitidos por los responsables de los Centros Asociados. Esta evaluación tendrá como objetivo valorar el desempeño de la actividad desarrollada por el tutor y su adecuación al plan docente elaborado por el equipo responsable de la asignatura. Esta evaluación forma parte de los procedimientos previstos en los sistemas de garantía de calidad de los títulos de Espacio Europeo. La evaluación se llevara a cabo a partir de dictámenes facilitados por la Universidad y del autoinforme o plan de mejora presentado por el propio profesor tutor. Por último, cuando el número de matriculados en alguna asignatura sea reducido incluso a nivel de Campus, el Rectorado, de acuerdo con los Coordinadores, arbitrará soluciones de carácter general. Por lo tanto, el seguimiento de un estudiante, en función del número de los matriculados en la asignatura, podrá ser llevado a cabo por: Un profesor tutor de su Centro Asociado. Un profesor tutor del Campus en el que esté integrado el Centro. Un profesor tutor que atienda estudiantes de varios Campus. Se procurará que cada Centro tenga asignadas tutorizaciones de Campus de forma proporcional a su número de estudiantes. Cuando no pudiera ser así, se establecerán mecanismos de compensación similares a los que actualmente se aplican por la realización de prácticas de laboratorio» ${ }^{19}$.

19 Digo discutido porque mereció el voto en contra por ejemplo de la autora de estas líneas y por ha sido objeto de contestación por parte de la representación del colectivo afectado, intentada infructuosamente el pasado día 22 de abril de 2009 en la Comisión de Metodología. 


\section{DEPARTAMENTOS Y UNIDADES, ÁMBITOS Y ÁREAS DE CONOCIMIENTO: LA FUNCIÓN DOCENTE}

\section{IV.1. Cuestiones sobre la reforma de la estructura de los departamentos: de órganos a unidades administrativas}

Ya se ha destacado que la Universidad española está sometida a un proceso de cambios tan profundo que se puede decir, sin excederse, que todos y cada uno de sus componentes han sufrido algún tipo de modificación en los últimos diez años ${ }^{20}$. En particular, el factor normativo con que se inicia este proceso es la Ley Orgánica 6/2001, de 21 de diciembre, de Universidades, con el que se emprende la renovación de su régimen jurídico. En este sentido, téngase en cuenta que pocos años después de la promulgación de aquella Ley, el legislador aprueba otra importante modificación que altera casi el ochenta por ciento del articulado original.

Aquella última reforma, operada por la Ley Orgánica 4/2007, de 12 de abril, entre otras cuestiones, modifica profundamente la actual configuración departamental. Así, la nueva redacción dada al artículo noveno sobre los Departamentos dice: «1. Los departamentos son las unidades de docencia e investigación encargadas de coordinar las enseñanzas de uno o varios ámbitos de conocimiento en uno o varios centros, de acuerdo con la programación docente de la universidad, de apoyar las actividades e iniciativas docentes e investigadoras del profesorado, y de ejercer aquellas otras que sean determinadas por los estatutos. 2. La creación, modificación y supresión de departamentos corresponde a la universidad, conforme a sus estatutos ${ }^{21}$.

Conviene retener que con dicha redacción los Departamentos han pasado de la categoría de "órganos" a «unidades» ${ }^{22}$. Por su

$20 \mathrm{Vid}$., la Comunicación presentada al I Congreso Internacional Diplaes 2008: Nuevas Bases para el diseño de los Planes de Estudio en el EEE y su incidencia en el sistema educativo, celebrado en Madrid del 22 al 26 de abril de 2008, titulada «Departamentos, asignaturas y áreas de conocimiento: La reasignación de la docencia ante el EEES».

${ }^{21} \mathrm{Vid}$., después lo que se dirá sobre la enmienda que propuso sustituir la mención a las áreas por ámbitos.

${ }^{22}$ Dice el artículo 5 de la Ley 6/1997, de 14 de abril, de Organización y funcionamiento de la Administración General del Estado, que «tendrán consideración de órganos las unidades administrativas a las que se les atribuyan funciones que tengan efectos jurídicos frente a terceros, o cuya actuación tenga carácter preceptivo»; y concreta el artículo 7 que «las unidades administrativas son los elementos organizativos básicos de las estructuras orgánicas. Las unidades comprenden puestos de trabajo o dotaciones de plantilla vinculados funcionalmente por razón de sus cometidos y orgánicamente por una jefatura común...». 
parte, este cambio impuesto por la mencionada reforma, en el momento de redactar estas líneas y haciendo para ello uso del término de adaptación estatutaria prevista en la Disposición adicional octa$\mathrm{va}^{23}$, no ha sido aplicado a los Estatutos de la UNED donde éstos fueron diseñaron como «órganos encargados de coordinar las enseñanzas de una o varias áreas de conocimiento en una o varias áreas de conocimiento en uno o varios centros, para procurar la mejor programación docente de la universidad y de apoyar las actividades e iniciativas de investigación de sus miembros» ${ }^{24}$.

\section{IV.2. De las asignaturas y áreas de conocimiento en el EEES: las cinco ramas y las materias de cada rama}

Sentadas estas premisas sobre la noción legal de los Departamentos, corresponde ahora anticipar alguno de los datos básicos acerca de la asignatura y el área de conocimiento. Las áreas de conocimiento en la Ley Orgánica 6/2001, de 21 de diciembre, de Universidades y como sucedió con la Ley de Reforma Universitaria, se convirtieron en criterio básico del procedimiento de habilitación del profesorado tanto para la selección como para la composición de las comisiones de evaluación ${ }^{25}$.

La particularidad que diferencia el sistema fijado en 2001 frente al 1983 es la definitiva consagración del concepto y atribución

${ }^{23}$ Literalmente declara: «Las Universidades adaptarán sus estatutos conforme a lo dispuesto en la presente Ley en un plazo máximo de tres años. Hasta tanto se produzca la adaptación de los Estatutos, los Consejos de Gobierno de las universidades podrán aprobar la normativa de aplicación que sea necesaria para el cumplimiento de lo establecido en esta Ley». En el último Claustro celebrado el 23 de junio de 2008 así como en el Consejo de Gobierno del día siguiente, el Rectorado manifestó su intención de optar por acuerdos en el seno del Consejo antes de la modificación estatutaria, pospuesta a otro momento.

${ }^{24}$ Artículo 47 de los Estatutos de la UNED (Real Decreto 426/2005, de 15 de abril, por el que se aprueban los Estatutos de la Universidad Nacional de Educación a Distancia).

${ }^{25}$ En la materia he tenido en cuenta la comunicación presentada al V Foro sobre la Evaluación de la Calidad de la Educación Superior y de la Investigación, que llevaba por título «De las asignaturas jurídico-formativas a las materias básicas en el grado de Derecho: el papel de las áreas ante el profesorado acreditado por rama de conocimiento", cuyo resumen se y vínculo al texto completo está incorporado al libro electrónico con ISBN 987-84-691-3972-1. Por su parte, y como dice el artículo 71 de la Ley Orgánica 6/2001, de 21 de diciembre, que «se entenderá por área de conocimiento aquellos campos del saber caracterizados por la homogeneidad de su objeto de conocimiento, una común tradición histórica y la existencia de comunidades de profesores e investigadores, nacionales o internacionales». 
competencial al Gobierno para la aprobación del Catálogo. En este punto, recuérdese que la LRU ni definía ni imputaba en el encargo de su elaboración a otro ámbito que el reglamentario.

Por su parte y con la reforma que se opera en 2007 sobre el sistema consagrado en el 2001, se mantiene el concepto y competencia en materia de áreas de conocimiento, si bien al alterarse el sistema de habilitación que se sustituye por el de acreditación y concurso de acceso posterior, se eliminan las referencias a las áreas como cualidades que adornan a los miembros de las comisiones de selección por otras referencias más genéricas en los términos que ahora veremos.

En cuanto a la asignatura, ésta resulta ser la concreción específica de alguna de las materias generales de los planes. Y este es el punto que queremos destacar, ya que al entremezclarse las nociones de áreas, con la de materias, ramas y asignaturas para la elaboración de los nuevos planes, aparentemente se despega la noción del área de cualquier otra implicación que no sea la de la selección del profesorado, explícitamente en el sistema de 2001 y más atemperadamente después en el de 2007, pese a la pervivencia de la referencia para las relaciones de puestos de trabajo del profesorado funcionario.

En este sentido, téngase en cuenta que el legislador de 2001 y para evitar las dudas puestas de manifiesto por el Tribunal Constitucional -en su Sentencia 26/1987, de 27 de febrero, sobre el sistema de 1983- decidió incorporar expresamente en el texto la noción del área de conocimiento si bien privada de carácter de Ley Orgánica $^{26}$. Adicionalmente y refrendado la doctrina constitucional amparada en el sistema de acceso aprobado en el año 83, ratificó su tradicional inclusión como cualidad específica de las comisiones de evaluación.

De lo anterior se deducen ciertas consecuencias ya que, atendiendo al alcance de la autonomía universitaria así como su intelección jurisprudencial sobre la organización de la docencia, se perpetúa la capacidad de los órganos de gobierno universitario para reasignar asignaturas así como la posibilidad de que sustentándose en dichos argumentos se altere o limite la función docente. Con todo y

${ }^{26}$ Vid., la Disposición adicional cuarta, sobre el carácter de Ley orgánica de la Ley 6/2001, donde entre otros, se exceptúa de este carácter al Capítulo I De las Universidades públicas que comprende tanto la sección primera Del personal docente e Investigador contratado y la sección segunda Del profesorado de los cuerpos docentes universitarios del Título IX Del profesorado. 
con la reforma de 2007 aparentemente se modifica sustancialmente el sistema de asignación de la docencia por vinculación al área, ya que, a su vez, desaparece la vinculación de las asignaturas a las área, resultando de esta forma un sistema inconsistente ahondada esta sensación por la modificación de la Ley Orgánica de 2001 hecha en el 2007 y su inmediato desarrollo reglamentario posterior.

\section{IV.3. De las áreas de conocimiento a los «ámbitos» de conocimiento}

\section{IV.3.1. Las áreas de conocimiento en la Ley de Reforma Universitaria de 1983 y el Tribunal Constitucional: comisiones y catálogos}

Como ya se ha recordado, la Ley Orgánica 11/1983, de 25 de agosto, de Reforma Universitaria, no contemplaba explícitamente el concepto de área de conocimiento si bien ésta se convertía en elemento necesario tanto para la creación de órganos departamentales como para la constitución de las correspondientes comisiones juzgadoras de los futuros funcionarios.

En particular, la LRU definía a los Departamentos en su artículo octavo como: «1. Los Departamentos son los órganos básicos encargados de organizar y desarrollar la investigación y las enseñanzas propias de su respectiva área de conocimiento en una o varias Facultades, Escuelas Técnicas Superiores, Escuelas Universitarias y, en su caso, en aquellos otros centros que se hayan creado al amparo de lo previsto en el artículo 7 de esta Ley. 2. Los Departamentos se constituirán por áreas de conocimiento científico, técnico o artístico, y agruparán a todos los docentes e investigadores cuyas especialidades se correspondan con tales áreas. 3. Asimismo, corresponde a los Departamentos la articulación y coordinación de las enseñanzas y de las actividades investigadoras de las Universidades. 4. La creación, modificación y supresión de Departamentos corresponderá a la Universidad respectiva conforme a sus Estatutos y de acuerdo con las normas básicas, aprobadas por el Gobierno a propuesta del Consejo de Universidades. 5. La dirección de cada Departamento corresponderá a uno de sus catedráticos, y, de no haber candidato de esa categoría, a uno de sus profesores titulares. Sus funciones serán determinadas en los Estatutos de la Universidad ${ }^{27}$.

27 BOE núm. 209, de 1 de septiembre de 1983. 
En este punto y en cuanto a la Sentencia del Tribunal Constitucional 26/1987, de 27 de febrero ${ }^{28}$, resolvió el Recurso de inconstitucionalidad presentado por el Gobierno Vasco contra determinados preceptos de la Ley Orgánica 11/1983, de 25 de agosto, de reforma universitaria. En su virtud, dicha resolución fijó la doctrina sobre la determinación de áreas de conocimiento y con ello anticipó el sentido del futuro artículo 71 de la Ley Orgánica de 2001 y refrendó también el contenido y alcance de la autonomía universitaria para su asignación y determinación.

Dice el Fundamento jurídico 12, en su punto tercero: «Se impugna también el núm. 3 de los arts. 35, 36, 37 y 38 de la LRU, que regulan la composición de las Comisiones a las que corresponde resolver los concursos para la provisión de plazas de Profesores titulares y Catedráticos en las Escuelas Universitarias (arts. 35 y 36) y en las Universidades (arts. 37 y 38). Integrarán estas Comisiones, según las normas impugnadas, cinco profesores "del área de conocimiento a la que corresponda la plaza", de los cuales dos (el presidente y un vocal) serán nombrados "por la Universidad correspondiente en la forma que prevean sus Estatutos", y los tres vocales restantes "serán designados mediante sorteo por el Consejo de Universidades y según el procedimiento que reglamentariamente establezca el Gobierno" ».

Sigue la Sentencia concretando que: «La impugnación está referida a los dos extremos siguientes: La determinación del área de conocimiento y la composición de las Comisiones y procedimiento para su formación. a) Respecto del primer punto, razona el recurso que no está claro que la determinación del "área de conocimiento" a que se refieren estos artículos, corresponda a las respectivas Universidades y, por entender que debe ser función de ellas en virtud de su autonomía, se impugnan estos preceptos. Es cierto que ni en estos artículos ni en ningún otro de la LRU se establece de forma expresa el concepto de áreas de conocimiento ni tampoco a quién corresponde la competencia para su determinación. De ahí que el recurso, partiendo de esta duda, la despeje en el sentido de que debe corresponder a la autonomía universitaria y no a la legislación estatal. En principio, teniendo en cuenta lo dispuesto en el art. 3.2 g), de la propia ley, que comprende como propio de la autonomía universitaria "la creación de estructuras especificas que actúen como soporte de la investigación y la docencia", sería correcto el plan-

${ }^{28}$ BOE: 19870324, núm. 71, dictada en Pleno por los Excmos. Sres. Tomás, Begué, Latorre, Rubio, Díez-Picazo, Truyol, García-Mon, de la Vega, Díaz, Rodríguez-Piñero, Leguina y López, siendo Ponente: don Fernando García-Mon y González-Regueral. 
teamiento del Gobierno Vasco, pero, como el área de conocimientos a que se refieren estos apartados es un presupuesto para la formación de las Comisiones que han de resolver los concursos de acceso a los Cuerpos docentes universitarios y para éstos se ha optado por el sistema funcionarial (art. 33 de LRU), no puede tacharse de inconstitucional su regulación por el Estado en virtud de lo dispuesto en el art. 149.1.18. ${ }^{a}$ de la Constitución ${ }^{29}$. Ahora bien, como la designación de los profesores integrantes de las Comisiones que han de resolver los concursos se hace con referencia al "área de conocimiento a la que corresponda la plaza", tiene que darse una homogeneidad real entre el objeto de conocimiento que sirve de base para la configuración de las áreas y las plazas a las que corresponda el concurso. Porque lo que en todo caso ha de respetarse en esta materia, por ser exigencia constitucional, es que el acceso a los Cuerpos docentes se regule en condiciones de igualdad (art. 23.2 de la C.E.) y "de acuerdo con los principios de mérito y capacidad" que establece el art. 103.3 de la Constitución, principios que están expresamente recogidos en el art. 41.1 de la LRU. La efectividad de este precepto requiere, en garantía de los derechos constitucionales que salvaguarda, que las áreas de conocimiento a efectos de la designación de los miembros de las Comisiones encargados de resolver los concursos sean homogéneos respecto de las plazas objeto del concurso. Esta homogeneidad entre áreas de conocimiento y plazas del concurso ha de darse necesariamente para que la "competencia científica" de los miembros de las Comisiones a que expresamente alude el núm. 2 del art. 41 de la LRU, esté referida a los conocimientos propios que correspondan a las plazas objeto del mismo».

${ }_{29}$ Por su parte, y en cuanto a la todavía vigente redacción del artículo 71 de la Ley Orgánica de Universidades 6/2001, se propuso como enmienda siendo el primer firmante el Grupo Parlamentario Vasco (EAJ-PNV) Al artículo 71.2 De modificación «En el seno del Consejo de Coordinación Universitaria se acordará y, en su caso, revisará el catálogo de áreas de conocimiento». Justificando su propuesta con los siguientes argumentos: "Adecuar a un correcto tratamiento técnico y a las normas constitucionales de reparto competencial la regulación sobre establecimiento de áreas de conocimiento, que debe ser sin lugar a dudas un aspecto que forma parte de la autonomía universitaria, dadas sus implicaciones académicas y organizacionales, sin perjuicio de que requiere de una coordinación global. Aquí se demuestra uno de los contenidos definidos por el TC para integrar la función de coordinación general: "establecer medios y sistemas que hagan posible la homogeneidad en aspectos técnicos". Huelga decir, en definitiva, que esta función no puede corresponder al Gobierno estatal». (Boletín Oficial de las Cortes Serie A: Proyectos de Ley, 13 de octubre de 2001, núm. 45-5, pág. 101). 
Respecto del segundo punto, es decir, la composición y procedimiento para la formación de las comisiones de selección dice: «b) Se impugna la composición de las Comisiones y el procedimiento para formarlas por estimar que no tienen carácter básico, dado que no son nacionales los Cuerpos de funcionarios docentes previstos en el art. 33 de la LRU, motivo por el cual la composición de las Comisiones y el procedimiento para formarlas debe corresponder a las Universidades en virtud de su autonomía y, subsidiariamente, a la Comunidad Autónoma en razón de las competencias que le corresponden con arreglo a los artículos 10.4 y 16 de su Estatuto. No puede admitirse, sin embargo, esta posición subsidiaria, porque los profesores de los Cuerpos a que se refiere el art. 33 de la LRU, no son "funcionarios del País Vasco o de su Administración Local", únicos funcionarios a que se refiere el art. 10.4 del EAPV. Tampoco puede estimarse el argumento principal que atribuye esta competencia a cada Universidad en virtud de su autonomía, ya que, una vez establecido el sistema funcionarial de los Cuerpos docentes universitarios en el art. 33 de la LRU, expresamente admitido por la recurrente, es inherente a ese sistema la existencia de un régimen uniforme de acceso y selección del profesorado en todas las Universidades. Porque, si bien inicialmente son funcionarios de la Universidad para la que son nombrados, ello no impide su traslado a otras Universidades mediante los concursos de méritos regulados por la ley, y esta condición de funcionarios interuniversitario, o "comunicables" entre las diferentes Universidades, justifica la aplicación al caso de las competencias exclusivas del Estado que se determinan en el art. 149.1.1 ${ }^{\mathrm{a}} \mathrm{y}$, especialmente, en el 149.1.18 a de la Constitución. Es preciso insistir que en esta materia de nombramientos o acceso a los Cuerpos docentes, la exigencia que establece el art. 41 de la LRU en sus dos apartados, por ser reflejo de lo que prescribe la Constitución en sus arts. 23.2 y 103.3, habrá de ser la base de los concursos por ella regulados y de los procedimientos a seguir para los nombramientos».

En su virtud, el Fallo de la resolución sobre los aspectos ahora tratados declara que «no es contrario a la Constitución el art. 8, apartado 4, de la Ley de Reforma Universitaria, interpretado conforme al fundamento jurídico $7 .^{\circ}$, apartado a): que tampoco lo es el art. 26, apartados 1 y 2 , interpretados conforme al fundamento jurídico 10 , apartado a), y que, asimismo, no son contrarios a la Constitución, en lo relativo a las áreas de conocimiento en ellos mencionadas, los apartados 3 de los arts. 35, 36, 37 y 38 de la citada Ley, interpretados conforme al fundamento jurídico 12 , apartado 3 a)». 


\section{IV.3.2. La noción área de conocimiento: su incorporación expresa sin carácter orgánico según la Ley Orgánica 6/2001, de 21 de diciembre, de Universidades}

Téngase en cuenta que en el debate parlamentario se alzaron voces en contra del sistema de habilitación así como del referido a la determinación de las áreas de conocimiento. En este sentido, se desestimaron críticas al articulado como la presentada por el Grupo Parlamentario Federal de Izquierda Unida que decía que «el reto de mejorar la gestión universitaria no se puede enfocar desde la creación de unas condiciones rígidas en su estructura de organización interna, ni desde soluciones drásticas que intensifican la vinculación de la docencia a las áreas de conocimiento, ni en fin, desde la intervención funcional definitiva que supone una vida universitaria marcada por un componente regulador externo completo y con posibilidades de incrementarse en el futuro $»^{30}$.

Finalmente se ratificó la visión del Proyecto de Ley del Gobierno del PP entonces y finalmente se aprobó el artículo 71 que literalmente dice: "Áreas de conocimiento. 1. Las denominaciones de las plazas de la relación de puestos de trabajo de profesores funcionarios de cuerpos docentes universitarios corresponderán a las de las áreas de conocimiento existentes. A tales efectos, se entenderá por área de conocimiento aquellos campos del saber caracterizados por la homogeneidad de su objeto de conocimiento, una común tradición histórica y la existencia de comunidades de profesores e investigadores, nacionales o internacionales. 2. El Gobierno establecerá y, en su caso, revisará el catálogo de áreas de conocimiento, previo informe del Consejo de Coordinación Universitaria $^{31} »$.

Este precepto no ha sido modificado por la Ley Orgánica 4/2007, cuestión que merece ser destacada ya que esta norma ha alterado la práctica totalidad del articulado original de la Ley, poco más de veinte artículos perviven con la redacción original. Añádase a lo dicho sobre la reforma del artículo 9 de los Departamentos lo que ahora se verá.

30 BO VII Legislatura, 13 de octubre de 2001, pág. 45.

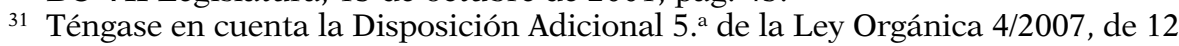
de abril, donde se advierte que las referencias al Consejo de Coordinación Universitaria del apartado segundo de este artículo deben entenderse hechas al Consejo de Universidades. 


\section{IV.3.3. Aparición de los «ámbitos» para sustituir a las "áreas» de conocimiento en el debate parlamentario}

Es bueno repasar el iter parlamentario de una norma, toda vez que en ocasiones con ello cobran sentido ciertas aparentes incoherencias $^{32}$. En este sentido y por su parte, la enmienda que afectó directamente a los Departamentos es la núm. 162, siendo firmante el Grupo Parlamentario Catalán (Convergència i Unió). Presentada «A los efectos de adicionar un apartado nuevo al artículo único para modificar el artículo 9 de dicha Ley: Redacción que se propone: Artículo único. La Ley Orgánica 6/2001, de 21 de diciembre, de Universidades, se modifica en los siguientes términos: Apartado nuevo». El artículo 9 queda redactado del siguiente modo: «1. Los Departamentos son los órganos encargados de coordinar las enseñanzas de uno o varios ámbitos del conocimiento en uno o varios centros, de acuerdo con la programación docente de la Universidad, de apoyar las actividades e iniciativas docentes e investigadoras del profesorado, y de ejercer aquellas otras funciones que sean determinadas por los Estatutos. 2. La creación, modificación y supresión de Departamentos corresponde a la Universidad conforme a sus Estatutos».

Por su parte, la justificación de dicha enmienda dice: «En el apartado 1, debería suprimirse áreas de conocimiento y sustituir la palabra por "ámbito", concepto que permitiría mayor interdisciplinariedad. La modificación del apartado 2 vigente, favorece la autonomía universitaria y agiliza los procedimientos, lo cual permite

${ }^{32}$ En este sentido, la noción de dependencia se incorporó al Código civil de forma previa a su configuración jurídica y técnica. Así el artículo 68, según la redacción dada por la Ley 15/2005, de 18 de julio, por la que se modifican el Código Civil y la Ley de Enjuiciamiento civil en materia de separación y divorcio (BOE de 9 de julio de 2005), determinó que «los cónyuges están obligados a vivir juntos, guardarse fidelidad y socorrerse mutuamente. Deberán, además, compartir las responsabilidades domésticas y el cuidado y atención de ascendientes y descendientes y otras personas dependientes a su cargo» Lo cierto es que el artículo 68 no estaba incluido en el texto inicial del Proyecto presentado a las Cortes -Proyecto de Ley núm. 121/000016- (vid., BOCG, VIII Legislatura, Serie A, 1 de diciembre de 2004); antes bien es la enmienda núm. 37 del Grupo Parlamentario Vasco (EAJ-PNV) la que insta la adición del artículo 68 en el sentido finalmente aprobado. La justificación alegada se limitaba a fundar la enmienda de adición en "proclamar la igualdad en aspectos considerados responsabilidad exclusiva o preferente de la mujer» (vid., BOCG, VIII Legislatura, Serie A, 15 de marzo de 2005) [vid., MORETÓN SANZ, «El nuevo sistema de protección de la persona con autonomía limitada: de la incapacitación judicial a la discapacidad y dependencia», en LASARTE ÁLVAREZ (Dir.) y MORETÓN SANZ (Coord.), La protección de las personas mayores, Tecnos, Madrid, 2007, págs. 31 a 49]. 
una cierta heterogeneidad que favorecerá, sin duda, la necesaria competencia universitaria ${ }^{33}$.

\section{IV.4. La función docente: los límites basados en la organización de la docencia}

Por su parte, el artículo 33 cuyo tenor literal no ha sido afectado por la reforma de 2007, presenta la particularidad frente a las libertades mencionadas en el artículo segundo, de los límites que pesan sobre la función docente concretados por las necesidades de organización.

Y dice el artículo 33 sobre la función docente: «1. Las enseñanzas para el ejercicio de profesiones que requieren conocimientos científicos, técnicos o artísticos, y la transmisión de la cultura son misiones esenciales de la Universidad. 2. La docencia es un derecho y un deber de los profesores de las Universidades que ejercerán con libertad de cátedra, sin más límites que los establecidos en la Constitución y en las leyes y los derivados de la organización de las enseñanzas en sus Universidades. 3. La actividad y la dedicación docente, así como la formación del personal docente de las Universidades, serán criterios relevantes, atendida su oportuna evaluación, para determinar su eficiencia en el desarrollo de su actividad profesional».

De modo que es posible por razón de servicio que un profesor o profesora sea reasignado también a otra disciplina distinta, cuestión que permite traer a colación un texto del Siglo XIX que en estos aspectos convenía en que «tampoco podrá ningún profesor ser traslado a otro establecimiento o asignatura sin previa consulta del Real Consejo de instrucción pública» ${ }^{34}$.

Como es sabido, las Universidades han hecho un ejercicio intenso de esta especificación de la autonomía, así en el caso de la UNED en su Reglamento de concurso de acceso a Cuerpos docentes (para profesorado habilitado) de 31 de marzo de 2004, en el artículo

33 Boletín Oficial de las Cortes Generales. Congreso de los Diputados. VIII Legislatura. Serie A. Proyecto de Ley, 28 de noviembre de 2006, núm. 101-109, pág. 83. Apréciese también en este Boletín los esfuerzos por parte del Grupo Parlamentario del Partido Popular, para mantener el sistema de habilitación del profesorado con mención explícita a las áreas de conocimiento (pág. 167).

34 Plan 1857 [PESET y PESET, La Universidad española (Siglos XVIII y XIX). Despotismo ilustrado y revolución liberal, Madrid, 1974, pág. 507]. 
primero se advierte de la potencial reasignación de docencia e investigación.

Por su parte y en vía judicial no se han amparado pretensiones que convenía en otra línea y en este sentido la Sentencia del Tribunal Superior de Justicia del Principado de Asturias, del 4 de mayo de 1998 advertía que «el hecho que una determinada asignatura del plan de estudios de una Facultado e Escuela Técnica Superior, se incluya en un Área de Conocimiento o en otra y en consecuencia, pertenezca a un Departamento o a otro es una cuestión de política universitaria que corresponde decidida a la junta de gobierno de la Universidad en virtud de la autonomía universitaria reconocida en la Constitución».

De modo que con este sistema de limitación de la docencia por cuestiones organizativas y de sistema, sin garantía de la cualificación específica del profesorado para la materia que imparte, bien parece que se regresa al sistema del primer tercio del Siglo XIX en que "cada cátedra, hasta 1824 tenían una remuneración distinta, muy variable. Se clasificaban - según fuese vitalicias o no- en de propiedad o de regencia, y según el rango de la disciplina, sería de entrada, ascenso y término. Las más importantes son las de prima, que explican por la mañana y, algo menos, las de vísperas por la tarde. Solían entrarse por las de regencia y se iba saltando de una disciplina a otra, dentro de la misma facultad, hasta llegar a ocupar la de primera; en Valencia, hasta las pavordrías, que llevaban aneja la dignidad eclesiástica y mejor salario. Con el tiempo, cada catedrático se asirá a una disciplina peculiar, pero esta especialización no se alcanza hasta bien entrado el siglo siguiente (...). La única obligación de los profesores respecto de la universidad era la moralidad y cumplimiento de sus deberes docentes. En absoluto se veían constreñidos —ni animados - a la investigación; a lo más, se les pide que redacten algún libro de texto, o ellos lo redactan para su medro» ${ }^{35}$.

Recuérdese el tenor del artículo 2.3 cuya redacción sobre la Autonomía Universitaria mantiene la del texto de 2001 y con carácter de Ley Orgánica que «La actividad de la Universidad, así como su autonomía, se fundan en el principio de libertad académica que se manifiesta en las libertades de cátedra ${ }^{36}$, de investigación y de estudio».

35 PESET y PESET, La Universidad española (Siglos XVIII y XIX). Despotismo ilustrado y revolución liberal, Madrid, 1974, págs. 195 y sigs.

36 Sobre esta libertad atribuida a todos los docentes, vid., LOZANO CUTANDA, La libertad de cátedra, Madrid, 1995, págs. 108 y sigs. Cuestión distinta es la propiedad intelectual y los derechos que ostenten sobre sus creaciones originales, especialmente, aquellas que se vean plasmadas en formatos digitales capaces de ser reproducidos en abierto. 


\section{EL SISTEMA PLURAL DE ACCESO A LA DOCENCIA UNIVERSITARIA}

\section{V.1. Planteamiento: la convivencia de hasta tres sistemas de acceso a la docencia universitaria}

En las siguientes líneas se destacará ahora el difícil equilibrio que supone la convivencia de diversos sistemas de acceso a la docencia universitaria, con el protagonismo de las cinco ramas de conocimiento y sus materias básicas determinadas según el Real Decreto 1.393/2007, de 29 octubre, por el que se establece la ordenación de las enseñanzas universitarias oficiales ${ }^{37}$.

En este sentido, ha de tenerse presente la noción de área de conocimiento descrita como «campos del saber caracterizados por la homogeneidad de su objeto de conocimiento, una común tradición histórica y la existencia de comunidades de profesores e investigadores, nacionales o internacionales» ${ }^{38}$, se circunscribe en puridad a las relaciones de puestos de trabajo de profesorado funcionario. Con todo y como se verá en las líneas posteriores, esta limitación es meramente nominal, toda vez que sigue siendo el criterio básico para la composición y, en su caso, selección del candidato más idóneo a la plaza que queda adscrita a un área concreta $^{39}$.

Por su parte, la plantilla actual del profesorado se incorporó, en su momento, a sus Universidades y asignaturas por razón de la cualificación adquirida en su área, si bien en el año 2007 el legislador altera de nuevo el sistema de acceso a los cuerpos universitarios de 2001, obviando la referencia a las áreas de conocimiento, prefiriéndose una redacción más laxa en la que sólo se indica que las comisiones de selección deberán «contrastar sus capacidades para la exposición

37 Son cinco las Ramas de conocimiento: Artes y Humanidades; Ciencias; Ciencias de la Salud; Ciencias Sociales y Jurídicas y, por último, Ingeniería y Arquitectura. En particular y al estar dedicada profesionalmente al Derecho civil, destaco las materias básicas en la Rama de Ciencias Sociales y Jurídicas que son doce: Antropología (también está en Artes y Humanidades); Ciencia Política; Comunicación; Derecho; Economía; Educación; Empresa (también está en Ingeniería y Arquitectura); Estadística (también está en Ciencias de la Salud); Geografía (también está en Artes y Humanidades); Historia (también está en Artes y Humanidades); Psicología (también está en Ciencias de la Salud) y Sociología (también está en Artes y Humanidades).

38 De conformidad a lo previsto en el artículo 71 de la Ley Orgánica 6/2001, de 21 de diciembre, de Universidades.

39 Además así se ratifica el contenido del principio de capacidad y mérito del artículo 103 de la Constitución. 
y debate en la correspondiente materia o especialidad en sesión pública» ${ }^{40}$.

A las anteriores cuestiones se añade que la materialización del EEES impone la reducción temporal de las licenciaturas y la adscripción de títulos a una rama ${ }^{41}$. En este punto y en cada una de las cinco ramas se determinan las materias básicas, por lo que si los grados están destinados a proporcionar una formación general en una o varias disciplinas, no se acierta a comprender si con ello el profesorado deberá afrontar la reorientación de la especialización para la que fue seleccionado ya que cabe la posibilidad de que en el ejercicio también de la autonomía universitaria, cada Facultad apruebe sus planes en las que, en función de la negociación y «peso» de ciertas disciplinas, algunas cobren fuerza, otras nazcan para el Grado y otras desparezcan.

De modo que parece que la función docente, al estar sometida al límite del servicio y de la capacidad organizativa de cada Universidad (como manifestación de su autonomía universitaria), se convertirá en algo distinto de la libertad de investigación y más genéricamente de la de cátedra ${ }^{42}$.

Por tanto, se pretende contrastar si el sistema ideado es además de coherente con el compromiso social que asume, con la libertad de cátedra y con la propia especialización que ya tenían sus recursos humanos, o si este capital humano está llamado a una singular reconversión que puede no redundar en la «responsabilidad de la universidad de conectar al universitario con el sistema de ideas vivas de su tiempo ${ }^{43}$. Y todo ello, por cierto, a coste cero.

40 Tal y como determina ahora el artículo 62 de la Ley Orgánica de Universidades, según la nueva redacción operada por la Ley Orgánica 4/2007, de 12 de abril, donde fue eliminado el sistema de habilitación y con ello las menciones a las áreas de conocimiento. Como es sabido la Ley Orgánica 6/2001, se aprueba en el seno de la VII Legislatura donde las fuerzas políticas del Congreso no son idénticas a las de la VIII y actual IX Legislatura.

${ }_{41}$ Vid., el Real Decreto 1.393/2007, de 29 octubre, por el que se establece la ordenación de las enseñanzas universitarias oficiales.

${ }^{42}$ En el futuro Grado de Derecho de la UNED muchas de las interrogantes que afectaban a asignaturas llamadas a ocupar un espacio distinto del que presentan en los vigentes Planes elaborados a partir del de 1953. En particular y como es sabido, asignaturas jurídicas básicas (Derecho Romano, Historia del Derecho y de las Instituciones, Derecho Canónico o Eclesiástico del Estado o Filosofía del Derecho), han sido despejadas, manteniéndose en idénticos términos o mejorándose por la proporción crediticia pese a que algunas de ellas han sido eliminadas en otros planes como sucede con ciertas disciplinas de derecho no positivo en el caso universitario alemán.

43 Artículo 93 de la LOU según la redacción dada por la Ley Orgánica 4/2007, de 12 de abril. 


\subsection{El nuevo sistema de acreditaciones por rama de conocimiento}

\section{V.2.1. La ANECA como fundación estatal}

Por lo que se refiere a la evaluación previa que ha de obtener quien pretenda obtener la condición de Profesor Ayudante Doctor, Profesor Contratado Doctor o Colaborador, es competencia de la ANECA, singularmente por lo que se refiere al profesorado UNED, toda vez que el resto de las CCAA en el ejercicio de sus competencias han creado sus propias agencias de evaluación; frente al sistema de acreditación para la futura adquisición de la condición de funcionario ya que en este supuesto la competencia reside en exclusiva en la ANECA ${ }^{44}$.

En particular la ANECA se trata de una institución que ostenta la condición jurídica de fundación estatal creada el 19 de julio de 2002, en cumplimiento de lo establecido en la LOU. Expresamente sus funciones se refieren a la contribución de la mejora de la calidad del Sistema de educación superior, mediante evaluación, certificación y acreditación de enseñanzas, profesorado e instituciones ${ }^{45}$.

\section{V.2.2. Acreditación por ramas: la certificación nacional independientemente de la rama}

Lo cierto es que el Real Decreto 1.312/2007, de 5 de octubre, por el que se establece la acreditación nacional para el acceso a los cuerpos docentes universitarios, no contiene ninguna referencia

${ }_{44}$ Así lo determina el Real Decreto 1.312/2007, de 5 de octubre, por el que se establece la acreditación nacional para el acceso a los cuerpos docentes universitarios.

45 En particular, téngase en cuenta el Acuerdo por el que se autoriza al, entonces Ministerio de Educación, Cultura y Deporte, para crear la Fundación Agencia Nacional de Evaluación de la Calidad Acreditación, de acuerdo con lo previsto en el inciso final del apartado 5 del artículo 6 del texto refundido de la Ley General Presupuestaria, aprobado por el Real Decreto Legislativo 1091/1988, de 23 de septiembre, según la redacción efectuada por el artículo 44.uno de la Ley 14/2000, de 29 de diciembre, de Medidas Fiscales, Administrativas y del Orden Social, siendo el Protectorado de esta Fundación será ejercido por el Ministerio de Educación, Cultura y Deporte en los términos previstos por la Ley 30/1994, de 24 de noviembre, de Fundaciones y de Incentivos Fiscales a la Participación Privada en Actividades de Interés General y el Real Decreto 316/1996, de 23 de febrero, por el que se aprueba el Reglamento de las fundaciones de competencia estatal. 
a áreas o ámbitos ${ }^{46}$ sino a las "ramas del conocimiento». Destaca especialmente la eficacia atribuida a la certificación de acreditación, toda vez que como anuncia la Exposición de Motivos, «el certificado de acreditación surtirá efectos en todo el territorio nacional y se configura, en última instancia, como garante de la calidad docente e investigadora de su titular al que habilitará para concurrir a los concursos de acceso a los cuerpos docentes convocados por las universidades, independientemente de la rama de conocimiento en la que el acreditado haya sido evaluado» ${ }^{47}$.

En consonancia con lo anterior, el artículo tercero concreta la finalidad de la acreditación nacional basada en «la obtención del correspondiente certificado de acreditación que constituye el requisito imprescindible para concurrir a los concursos de acceso a los cuerpos de profesorado funcionario docente a que se refiere el artículo 57.1 de la Ley Orgánica 6/2001, de 21 de diciembre, de acuerdo con los estándares internacionales evaluadores de la calidad docente e investigadora. La acreditación surtirá efectos en todo el territorio nacional para concurrir al cuerpo al que se refiera, independientemente de la rama $\mathrm{de}^{48}$ conocimiento en la que el acreditado haya sido evaluado, y tiene por objeto la valoración de los méritos y competencias de los aspirantes a fin de garantizar una posterior selección del profesorado funcionario eficaz, eficiente, transparente y objetiva».

La otra cuestión destacable es la que se refiere a las comisiones de acreditación, ya que se declara en el artículo cuarto que «se constituirán al menos una Comisión para cada una de las acreditaciones a

46 Excepto la referida a los criterios para la designación de los miembros de las comisiones, que en el artículo 6.2 declara que «se procurará que en las comisiones de acreditación haya miembros que desarrollen su actividad en distintos ámbitos científicos y académicos pertenecientes a diferentes instituciones y comunidades autónomas». O con más transcendencia, la contenida en el artículo 15 sobre los expertos que asesoran a las comisiones, que dice: «Las comisiones remitirán la documentación aportada por los solicitantes al menos a dos expertos del ámbito científico y académico correspondiente para la elaboración de sendos informes individuales. Los criterios de selección de los expertos y los procesos de actuación serán aprobados por el Consejo de Universidades previa propuesta de la Agencia Nacional de Evaluación de la Calidad y Acreditación. En el caso de que las comisiones lo consideren necesario, podrán solicitar informes adicionales. Para poder actuar como experto deberán cumplirse los mismos o equivalentes requisitos que para poder formar parte de la Comisión correspondiente».

47 Recojo aquí lo publicado en Una Universidad para el Siglo XXI: EEES (Una mirada transdisciplinar, ecoformadora e intercultural, MEDINA, SEVILLANO y TORRE (Coords.), Madrid, 2009, págs. 241 y sigs.

48 Aquí no es «del» conocimiento, como en la Exposición de Motivos transcrita sino sólo «de» conocimiento. 
que se refieren los artículos $12^{49}$ y $13^{50}$ y para cada una de las ramas del conocimiento siguientes: Artes y Humanidades; Ciencias; Ciencias de la Salud; Ciencias Sociales y Jurídicas, e Ingeniería y Arquitectura».

Por su parte, el desarrollo reglamentario efectuado por Resolución de 5 de diciembre de 2007, de la Secretaría General del Consejo de Coordinación Universitaria, por la que se publica el Acuerdo del Consejo de Universidades por el que se designan los miembros de las comisiones de acreditación nacional, sí recoge el área de conocimiento al que pertenecen si bien formando parte de una Comisión por ramas.

De modo que sucederá como en la evaluación para profesorado contratado, donde ésta se efectúa por afinidades al área de conocimiento donde se haya especializado el candidato, así por ejemplo, la evaluación del profesorado de Derecho se hará por un profesor de esta materia pero no por el área singular.

49 Acreditación para el acceso al Cuerpo de Titulares de Universidad, donde por cierto se contiene un doble efecto de la certificación de la acreditación, toda vez que en el caso de títulos extranjeros la emisión positiva confirme la cualidad de homologado al título no nacional.

50 Se refiere en este caso a la acreditación para el acceso al Cuerpo de Catedráticos de Universidad. En este sentido, recuérdese que «en el siglo XVI las cátedras se proveían por los votos de los estudiantes matriculados, sistema que — como otros- podía abocar en abusos y picaresca (...) Al fin, en los años iniciales del seiscientos, se decide cambiar la forma de provisión de cátedras, si bien Lérida o Valencia siguen en su sistema de patronato municipal (...) El método para elegirlos es sencillo, aunque parece de gran complejidad, cada tipo de cátedra —entrada, ascenso y término- es juzgada por determinados catedráticos. Deben ser de su mismo ramo y de mayor categoría, si es posible (...). La selección de los profesores tenía que preocupar siempre a la autoridad central. La universidad, cada vez más, se hallaba en manos de los catedráticos. En la antigua, donde los estudiantes y doctores tenían mayor importancia, eran ellos lo que decidían quiénes habían de ser profesores. Y era lógico, ya que la institución fue creada para ellos y la mantenían, en parte, con sus matrículas, ciencias y argucias políticas. Por eso resulta comprensible históricamente la designación primera de catedráticos por estudiantes, y -más tarde- por los doctores. Si bien, desde este momento la influencia colegial desplaza la decisión última al consejo de Castilla, que dominan» [PESET y PESET, La Universidad española (Siglos XVIII y XIX). Despotismo ilustrado y revolución liberal, Madrid, 1974, págs. 189 y sigs.]. «Después durante el Siglo liberal, la universidad pasaría de la iglesia al estado (...) Frente a la variedad, un cuerpo único como quería Napoleón» y los ejercicios son tres «un discurso sobre tema de la asignatura disputada», una lección y el tercero preguntas sueltas «extraídas por suerte de todas las materias de la asignatura»... sólo ha cambiado del sistema «el fuerte control desde el poder central que es quien dispensa el nombramiento» (ibidem, págs. 491 y sigs.). En particular según el artículo 12 del Real decreto de 1 de mayo de 1864 , los jueces serán nombrados por la Dirección general de Instrucción pública entre «Catedráticos y personas de graduación académica o de notable reputación en la ciencia a que pertenezca la vacante». 
En cuanto a los Expertos, la elaboración de la lista de miembros propuestos a partir de la información aportada por los candidatos, la Aneca informa sobre que «el procedimiento se inició con una convocatoria pública en la que se solicitaron voluntarios para formar parte de las comisiones. Con los formularios recibidos se realizó una base de datos que reúne la información aportada por los candidatos que es relevante para la selección. A partir de las áreas de conocimiento indicada por éstos, la base de datos se organizó en función de las ramas de conocimiento establecidas para la composición de las comisiones (Artes y Humanidades, Ciencias, Ciencias de la Salud, Ciencias Sociales y Jurídicas, e Ingeniería y Arquitectura) y los ámbitos científicos contemplados en cada una de ellas (que agrupan a las áreas de conocimiento, entre cuyos profesores adscritos se propone la selección de cada uno de los miembros de las comisiones de acreditación). A continuación la lista general se desagregó en listas separadas de solicitantes según cuerpo, género y ámbito científico» ${ }^{51}$.

Finalmente y en cuanto a las solicitudes, cabe destacar que la aplicación reclama la designación de la rama como del área de conocimiento de origen http://www.aneca.es/active/docs/academia_ expertos_sociales_090508.pdf 52 .

\section{V.2.3. La cuantificación de méritos para la acreditación nacional para el acceso a los cuerpos docentes: análisis particular del caso del cuerpo funcionarial de titulares y catedráticos de Universidad}

El mencionado Real Decreto 1.312/2007, por el que se establece la acreditación nacional para el acceso a los cuerpos docentes universitarios declara que uno de los ejes vertebradores de la reforma de la LOLOU no era otro que el del «la nueva configuración universitaria, que se manifiesta, por un lado, en la estructuración del personal docente universitario en dos únicos cuerpos, de Catedráticos de Universidad y de Profesores Titulares de Universidad, y, por otro, en el establecimiento de un nuevo modelo de acreditación de ele-

51 ANECA, 30 de noviembre de 2007. Por su parte, la lista del panel de expertos al día 15 de mayo de 2009 sólo indica la Universidad de procedencia con alguna indicación referida a que algún evaluador podrá hacer evaluaciones en varias ramas, al pertenecer a ámbitos de conocimiento compartidos.

52 ANECA, actualizado a 8 de mayo de 2009. 
gibles, en el que, a diferencia de la habilitación hasta ahora vigente, se ha eliminado la oferta de un número de plazas previamente delimitadas. Tal modelo se basa ahora en la previa posesión por el candidato o candidata de una acreditación nacional, cuyo procedimiento de obtención se regula en este Real Decreto y que permitirá a las universidades elegir a su profesorado, de manera mucho más eficiente, entre los previamente acreditados. El sistema planteado se inspira en la tradición académica de la evaluación por los pares».

Su Anexo presenta cuáles han de ser los criterios de evaluación y adicionalmente cuál será el baremo aplicable a uno u otro cuerpo:

\section{A. Criterios de evaluación}

1. Actividad investigadora. 1.A Calidad y difusión de resultados de la actividad investigadora.-Publicaciones científicas, creaciones artísticas profesionales, congresos, conferencias, seminarios, etcétera. 1.B Calidad y número de proyectos y contratos de investigación. 1.C Calidad de la transferencia de los resultados.-Patentes y productos con registro de propiedad intelectual, transferencia de conocimiento al sector productivo, etcétera. 1.D Movilidad del profesorado.-Estancias en centros de investigación, etc. 1.E Otros méritos.

2. Actividad docente o profesional. 2.A Dedicación docente.-Amplitud, diversidad, intensidad, responsabilidad, ciclos, tipo de docencia universitaria, dirección de tesis doctorales, etc. 2.B Calidad de la actividad docente.-Evaluaciones positivas de su actividad, material docente original, publicaciones docentes, proyectos de innovación docente, etcétera. 2.C Calidad de la formación docente.-Participación, como asistente o ponente, en congresos orientados a la formación docente universitaria, estancias en centros docentes, etc. 2.D Calidad y dedicación a actividades profesionales, en empresas, instituciones, organismos públicos de investigación u hospitales, distintas a las docentes o investigadoras.-Dedicación, evaluaciones positivas de su actividad, etc. 2.E Otros méritos.

3. Formación académica. 3.A Calidad de la formación predoctoral.-Becas, premios, otros títulos, etc. 3.B Calidad de la formación posdoctoral.-Becas posdoctorales, tesis doctoral, premio extraordinario de doctorado, mención de doctorado europeo, mención de calidad del programa de doctorado. 3.C Otros méritos de formación académica. 
4. Experiencia en gestión y administración educativa, científica, tecnológica y otros méritos. 4.A Desempeño de cargos unipersonales de responsabilidad en gestión universitaria recogidos en los estatutos de las universidades, o que hayan sido asimilados, u organismos públicos de investigación durante al menos un año. 4.B Desempeño de puestos en el entorno educativo, científico o tecnológico dentro de la Administración General del Estado o de las comunidades autónomas durante al menos un año. 4.C Otros méritos.

B. BAREmo por el que el Real Decreto concreta lo siguiente:

1. Para el cuerpo de Profesores Titulares de Universidad. El baremo será, para cada uno de los criterios del apartado A: a) Actividad investigadora: un máximo de 50 puntos. b) Actividad docente o profesional: un máximo de 40 puntos. c) Formación académica: un máximo de 5 puntos. d) Experiencia en gestión y administración educativa, científica, tecnológica y otros méritos: un máximo de 5 puntos. Para obtener la evaluación positiva han de cumplirse simultáneamente las siguientes condiciones: a) Alcanzar un mínimo de 60 puntos sumando los obtenidos en los apartados «1. Actividad investigadora « $\mathrm{y}$ «2. Actividad docente o profesional». b) Conseguir un mínimo de 65 puntos como suma de todos los apartados.

2. Para el cuerpo de Catedráticos de Universidad. El baremo será, para cada uno de los criterios del apartado A: a) Actividad investigadora: un máximo de 55 puntos. b) Actividad docente o profesional: un máximo de 35 puntos. c) Experiencia en gestión y administración educativa, científica, tecnológica y otros méritos: un máximo de 10 puntos. Para obtener la evaluación positiva han de cumplirse simultáneamente las siguientes condiciones: a) Conseguir un mínimo de 80 puntos como suma de todos los criterios. b) Conseguir al menos 20 puntos en el segundo criterio. Para la evaluación de la experiencia investigadora. En el caso de la valoración del apartado 1 "Actividad investigadora", la aportación de un periodo de actividad investigadora reconocido de acuerdo con las previsiones del Real Decreto 1.086/1989, de 28 de agosto, de retribuciones del profesorado universitario, tendrá una valoración de 15 puntos.

De conformidad a los criterios desarrollados en el ejercicio de sus funciones en el seno de la ANECA y disponibles en la siguiente dirección: http://www.aneca.es/active/docs/academia_principios_ y_orientaciones_080114.pdf la tabla orientativa de publicaciones má- 
ximas para titular de universidad se puede consultar ya que por razones técnicas no me ha resultado posible transcribirla. Con todo, los criterios específicos son:

- 2. Titular de Universidad. La Ley Orgánica 4/2007, de 12 de abril, por la que se modifica la Ley Orgánica 6/2001, de 21 de diciembre, de Universidades, establece en su artículo 59, que quienes posean el título de Doctor podrán presentar una solicitud para obtener la acreditación para Profesora o Profesor Titular de Universidad. Y el artículo 57, sobre la acreditación nacional, establece que el acceso a los cuerpos de funcionarios docentes universitarios exigirá la previa obtención de una acreditación nacional que, valorando los méritos y competencias de los aspirantes, garantice la calidad en la selección del profesorado funcionario. Por su parte, el Real Decreto $1.312 / 2007$, por el que se establece la acreditación nacional para el acceso a los cuerpos docentes universitarios, determina que la valoración de los méritos y competencias de los aspirantes para la obtención de la acreditación se realizará por comisiones de acreditación. Los miembros de tales comisiones han sido designados por el Consejo de Universidades entre los propuestos por la Agencia Nacional de Evaluación de la Calidad y Acreditación y rendirán cuentas de su actuación a dicha Agencia.

- El Anexo del mencionado Real Decreto fija cuatro grandes apartados de criterios de evaluación para las solicitudes de acreditación al Cuerpo de Profesores Titulares de Universidad: 1. Actividad investigadora. 2. Actividad docente o profesional. 3. Formación académica. 4. Experiencia en gestión y administración.

- Asimismo, establece el baremo de evaluación con puntuaciones máximas a otorgar en cada uno de los apartados anteriores que se resumen en la siguiente tabla 2.1. Además, el RD determina que para obtener una evaluación positiva se deben cumplir, en cada caso, dos requisitos simultáneamente que se indican en la tabla 2.2.

- Criterios de evaluación Acreditación para PTU

1. Actividad investigadora 50.

2. Actividad docente o profesional 40.

3. Formación académica 5.

4. Experiencia en gestión y administración 5. 
- Tabla 2.1. Puntuaciones máximas para el baremo fijado en el RD1312/2007: Requisitos para obtener una evaluación positiva: Acreditación para PTU: 1. Actividad investigadora. 2. Actividad docente o profesional Mínimo de 60 puntos entre ambos apartados SUMA TOTAL $1+2+3+4$ Mínimo de 65 puntos.

- Tabla 2.2. Requisitos mínimos para obtener una evaluación positiva según el RD1312/2007 En este documento de Principios y orientaciones para la aplicación de los criterios de evaluación se detallan los méritos a valorar en el proceso de evaluación de las solicitudes. Los méritos se agrupan en bloques de características homogéneas que pueden ser puntuados conjuntamente. A la vez, el documento incorpora tablas orientativas de puntuaciones máximas para cada uno de los apartados, diferenciadas por cada una de las cinco ramas. La estructura de bloques, junto con la relación de méritos a valorar y la estructura básica de puntuaciones se indican a continuación. La ponderación de los méritos no se limita a un mero cómputo administrativo, sino que las comisiones valoran principalmente los méritos asociados a las actividades de investigación, docentes, de formación académica y de gestión aportadas por el aspirante en su solicitud».

\section{V.2.4. Concursos de acceso: la capacitación de los miembros de las comisiones de selección}

Por cuanto se refiere a los concursos de acceso posteriores a la acreditación, el reciente Real Decreto 1.313/2007, de 5 de octubre, por el que se regula el régimen de los concursos de acceso a cuerpos docentes universitarios, reaparece el término área de conocimiento si bien referido al reingreso de excedentes al servicio activo ${ }^{53}$. En este

53 «El reingreso podrá efectuarse, asimismo, en la Universidad a la que perteneciera el centro universitario de procedencia con anterioridad a la excedencia, solicitando del Rector la adscripción provisional a una plaza de la misma, con la obligación de participar en cuantos concursos de acceso se convoquen por dicha Universidad para cubrir plazas en su cuerpo y área de conocimiento, perdiendo la adscripción provisional caso de no hacerlo. La adscripción provisional se hará en la forma y con los efectos que, respetando los principios reconocidos por la legislación general de funcionarios en el caso del reingreso al servicio activo, determinen los Estatutos. No obstante, el reingreso será automático y definitivo, a solicitud del interesado dirigida a la Universidad de origen, siempre que hubieren transcurrido, al menos, dos años en situación de excedencia, y que no excedieren de cinco, y si existe plaza vacante del mismo cuerpo y área de conocimiento». 
caso, esta mención no es fruto de ninguna modificación sino de la redacción original del artículo 67 de la Ley Orgánica 6/2001, de 21 de diciembre, que no ha sido alterado en el 2007.

Lo transcendente es lo referido, por tanto a las Comisiones de selección a cuyos miembros se les reclama que «1. Los Estatutos de cada Universidad regularán la composición de las comisiones de selección de las plazas convocadas y garantizarán, en todo caso, la necesaria aptitud científica y docente de sus componentes», en consonancia a su vez con la nueva redacción dada en 2007 al artículo 62 de la LOU. Adicionalmente la acreditación es mérito preferente para el acceso a la condición de profesorado contratado ${ }^{54}$.

En cuanto al desarrollo reglamentario, los modelos han ido desde el elegido por la Universidad Rey Juan Carlos I, que sencillamente transcribe el Real Decreto, al de la UNED, en el que se ha elegido por parte del actual equipo rectoral la prueba de temario exclusivamente para el cuerpo de titulares de Universidad $^{55}$.

\section{V.3. Profesorado contratado: el sistema y criterios de evaluación en la ANECA}

En cuanto a las plazas de profesorado en régimen laboral, que tanto tras la entrada en vigor de la LOU de 2001 como de la reforma de 2007, se siguen convocando por denominación y área de conocimiento resultando ser un criterio general para la baremación de los candidatos «Criterio general: Los méritos deberán ser siempre valorados en relación con el área de conocimiento a la que se adscribe la plaza objeto del concurso, así como con el perfil de la plaza, en su caso». Además, en consonancia con el artículo 174 de los Estatutos de la UNED, «se valorará preferentemente la preparación y experiencia en las técnicas y medios propios de la enseñanza a distancia $»^{56}$.

En cuanto a la UNED, se ha de añadir el contenido del Real Decreto 50/2004, de 19 de enero, por el que se regula el régimen del

${ }^{54}$ Artículo 48.

55 Aprobado por acuerdo de Consejo de Gobierno de 17 de noviembre de 2008 (Bici 8/Anexo I 24 de noviembre de 2008); con el voto en contra de la representación del profesorado contratado, del de ayudantes, del de catedráticos.

56 Resolución de 22 de febrero de 2009, de la Universidad Nacional de Educación a Distancia, por la que se acuerda la convocatoria 3/2009 de concursos a plazas de profesorado contratado en régimen laboral. 


\section{profesorado contratado de la Universidad Nacional de Educa- ción a Distancia ${ }^{57}$.}

En cuanto al procedimiento general del programa de evaluación de profesorado para la contratación de ANECA, se encuentra normalizado en el Real Decreto 1052/2002, de 11 de octubre, por el que se regula el procedimiento para la obtención de la evaluación de la Agencia Nacional de Evaluación de la Calidad y Acreditación, y de su certificación, a los efectos de contratación de personal docente e investigador universitario. A su vez y en cumplimiento de lo dispuesto en el apartado sexto de la Resolución de 18 de febrero de 2005, de la Dirección General de Universidades (BOE de 4 de marzo), se publica el documento de principios y orientaciones para la aplicación de los criterios de evaluación del Programa de Evaluación de Profesorado para la contratación.

Con todo y para clarificar la exposición se incorporan al texto los cuadros explicativos elaborados por la ANECA ya que con ello se visualiza con más facilidad los méritos alegables para la evaluación del Profesora Contratado doctor ${ }^{58}$ y para la de Ayudante doc-

57 Real Decreto 50/2004, de 19 de enero, por el que se regula el régimen del profesorado contratado de la Universidad Nacional de Educación a Distancia Artículo 14. Selección del personal docente e investigador contratado: 1. La selección del personal docente e investigador contratado a que se refiere este real decreto se efectuará mediante concurso público convocado por la UNED, con respeto a los principios constitucionales de igualdad, mérito y capacidad. Las convocatorias serán comunicadas en todo caso y con suficiente antelación al Consejo de Coordinación Universitaria para su difusión en todas las universidades. 2. Sólo podrán ser objeto de provisión aquellas plazas que previamente hayan sido incluidas en la correspondiente relación de puestos de trabajo del personal docente e investigador contratado laboral. 3. Los Estatutos de la Universidad regularán la composición y funcionamiento de los órganos de selección, así como el procedimiento selectivo. Los órganos de selección estarán compuestos por miembros de los cuerpos de funcionarios docentes universitarios y del personal docente contratado, que reúnan requisitos académicos iguales o superiores a los requeridos para el puesto de trabajo que se deba cubrir. 4. Los miembros de la comisión de selección deberán pertenecer al área de conocimiento a que corresponda la plaza objeto de provisión o, si ello no fuera posible, a otras áreas de conocimiento afines. 5. Se considerará mérito preferente para ser contratado estar habilitado, de conformidad con lo dispuesto en el art. 48.2 de la Ley Orgánica 6/2001, de 21 de diciembre, de Universidades, o pertenecer como funcionario a uno de los cuerpos docentes universitarios previstos en dicha ley.

58 ANEXO IV: Criterios de evaluación de la Agencia Nacional de Evaluación de la Calidad y acreditación para las figuras contractuales de profesorado Los siguientes criterios hacen referencia a la evaluación de los méritos que ha de realizar la Agencia Nacional de Evaluación de la Calidad y Acreditación previa a la contratación de profesorado, en cumplimiento de los artículos 50, 51, 52 y 72.2 de la Ley Orgánica 6/2001 de Universidades. Los Estatutos de las Universidades definirán los términos, criterios y procedimientos que se aplicarán en el proceso de contratación del profe- 


\section{tor $^{59}$ cuantificables así como su adaptación a las prescripciones de la reforma de la LOLOU:}

sorado referido en los citados artículos. 1. Profesor Contratado Doctor (artículo 52 de la Ley Orgánica 6/2001 de Universidades) y Profesor de Universidad Privada (artículo 72.2 de la Ley Orgánica 6/2001 de Universidades). Se valoran los siguientes tipos de méritos: experiencia investigadora, experiencia docente, formación académica y experiencia profesional, y otros méritos. Para obtener la acreditación han de cumplirse simultáneamente las siguientes condiciones: a) alcanzar un mínimo de 50 puntos sobre 100 sumando los obtenidos en los apartados de experiencia investigadora y de experiencia docente; b) conseguir un mínimo total de 55 puntos sobre 100 como suma de todos los apartados. 1.1 Experiencia investigadora.-Este apartado se valora hasta un máximo de 60 puntos sobre 100, teniendo en cuenta principalmente los siguientes méritos investigadores: 1.1.A Publicaciones científicas con proceso anónimo de revisión por pares y patentes internacionales en explotación. Se valoran preferentemente las aportaciones que sean artículos en revistas de prestigio reconocido, aceptándose como tales las que ocupen posiciones relevantes en los listados por ámbitos científicos en el «Subject Category Listing» del Journal Citation Reports del Science Citation Index, del Social Sciences Citation Index y del Arts and Humanities Citation Index (Institute of Scientific Information, -ISI- Philadelphia, PA, USA), en el Philosopher's Index, en el Répertoire Bibliographique de Louvain o similares. Las revistas incluidas en otras bases de datos internacionales, propias de determinados campos del saber, se consideran como una referencia de calidad. Las revistas electrónicas se valoran cuando aparezcan en los listados del ISI. Si ninguno de los ámbitos de estos listados se adecuara a la especialidad del solicitante, el Comité podrá utilizar otros que deberá hacer públicos. La valoración de la creatividad artística se realiza en función de su reconocimiento y de la repercusión producida a través de exposiciones, premios, concursos y certámenes. 1.1.B Libros y capítulos de libros para cuya evaluación se tiene en cuenta fundamentalmente su calidad avalada por el número de citas, el prestigio de la editorial, los editores, la colección en la que se publica la obra, las reseñas en las revistas científicas especializadas, su extensión y las traducciones a otras lenguas. 1.1.C Los proyectos de investigación obtenidos en convocatorias públicas y competitivas, en especial los financiados mediante programas nacionales, europeos u otros de ámbito internacional. Se tiene en cuenta especialmente el tipo de participación y grado de responsabilidad del solicitante. Los contratos de investigación de especial relevancia con empresas o con la administración pública. 1.1.D Otros resultados de la investigación, en especial los que produzcan transferencia tecnológica y contribuyan a la innovación del sector productivo, tales como patentes de ámbito nacional en explotación, prototipos, diseños, dictámenes, informes y otros. 1.1.E La dirección de tesis Doctorales valorándose especialmente: la mención de Doctorado europeo, la mención de calidad del programa de Doctorado, la calidad de los trabajos publicados relacionados con la misma y el prestigio de los centros en los que se ha llevado a cabo. 1.1.F Las contribuciones presentadas en congresos, conferencias, seminarios u otros tipos de reuniones de relevancia científica. 1.1.G Otros méritos de investigación no contemplados en los apartados anteriores. 1.2 Experiencia docente.-Este apartado se valora hasta un máximo de 30 puntos sobre 100, teniendo en cuenta principalmente los siguientes méritos docentes: 1.2.A La amplitud, la intensidad, el grado de responsabilidad, y los ciclos y tipo de la docencia en su ámbito disciplinar universitario en enseñanzas regladas y no regladas. Las instituciones nacionales o extranjeras en las que se ha ejercido la docencia, especialmente la desarrollada en centros diferentes al que se defendió la tesis Doctoral. 1.2.B Las evalua- 
Para obtener la evaluación positiva han de cumplirse simultáneamente las siguientes condiciones: a) alcanzar un mínimo de 50 puntos sobre 100 sumando los obtenidos en los apartados 1.1. «Experiencia investigadora» y 1.2. «Experiencia docente»; b) conseguir un mínimo de 55 puntos sobre 100 como suma de todos los apartados.

ciones que sobre la calidad de su docencia aporte el solicitante. 1.2.C La actuación como ponente en seminarios y cursos, y la participación en congresos específicamente orientados a la formación para la actividad docente universitaria. 1.2.D El desarrollo de material docente original del solicitante cualquiera que sea el soporte utilizado y las publicaciones (libros, artículos) relacionadas con la docencia, valorando especialmente su carácter innovador.

La participación en proyectos de innovación docente competitivos. La participación en planes y equipos de trabajo relacionados con el EEES. 1.3 Formación académica y experiencia profesional.-Este apartado se valora hasta un máximo de 8 puntos sobre 100, teniendo en cuenta principalmente los siguientes méritos: 1.3.A Se considera la calificación de la tesis, la mención de Doctorado europeo y la mención de calidad del programa de Doctorado. Se tienen en cuenta las becas pre y postDoctorales obtenidas en convocatorias competitivas, las estancias en otros centros atendiendo a su duración y a la calidad del programa y de la institución receptora, y también otros méritos de formación relevantes. Se valora especialmente la posesión de más de un título. 1.3.B Se valora la duración y la responsabilidad ejercida en empresas o instituciones, y su relevancia práctica para la docencia y la investigación. 1.4 Otros méritos.-Este apartado se valorará hasta un máximo de 2 puntos sobre 100. Se valora cualquier mérito de formación académica, docente, investigador, profesional o de gestión universitaria no contemplado en los criterios anteriores.

59 Los criterios para Profesor Ayudante Doctor (artículo 50 de la Ley Orgánica 6/2001, de Universidades). Se valoran los siguientes tipos de méritos: experiencia investigadora, formación académica, experiencia docente y profesional, y otros méritos. Para obtener la acreditación ha de cumplirse la siguiente condición: conseguir un mínimo total de 55 puntos sobre 100 como suma de todos los apartados. 2.1 Experiencia investigadora. Este apartado se valora hasta un máximo de 60 puntos sobre 100, teniendo en cuenta principalmente los siguientes méritos investigadores: 2.1.A Publicaciones científicas con proceso anónimo de revisión por pares. Se valoran preferentemente las aportaciones que sean artículos en revistas de prestigio reconocido, aceptándose como tales las que ocupen posiciones relevantes en los listados por ámbitos científicos en el «Subject Category Listing» del Journal Citation Reports del Science Citation Index, del Social Sciences Citation Index y del Arts and Humanities Citation Index (Institute of Scientific Information, -ISI- Philadelphia, PA, USA), en el Philosopher's Index, en el Répertoire Bibliographique de Louvain o similares. Las revistas incluidas en otras bases de datos internacionales, propias de determinados campos del saber, se consideran como una referencia de calidad. Las revistas electrónicas se valoran cuando aparezcan en los listados del ISI. Si ninguno de los ámbitos de estos listados se adecuara a la especialidad del solicitante, el Comité podrá utilizar otros que deberá hacer públicos. La valoración de la creatividad artística se realiza en función de su reconocimiento y de la repercusión producida a través de exposiciones, premios, concursos y certámenes. 2.1.B Libros y capítulos de libros para cuya evaluación se tiene en cuenta fundamentalmente su calidad avalada por el número de citas, el prestigio de la editorial, los editores, la colección en la que se publica 
la obra, las reseñas en las revistas científicas especializadas, la extensión y las traducciones a otras lenguas. 2.1.C La participación en proyectos de investigación obtenidos en convocatorias públicas y competitivas, en especial los financiados mediante programas nacionales, europeos u otros de ámbito internacional. La participación en contratos de investigación de especial relevancia con empresas o con la administración pública. 2.1.D Las contribuciones presentadas en congresos, conferencias, seminarios u otros tipos de reuniones de relevancia científica. 2.1.E Otros méritos de investigación no contemplados en los apartados anteriores. En especial se valora la participación en trabajos que produzcan transferencia tecnológica y contribuyan a la innovación del sector productivo. 2.2 Formación académica, experiencia docente y profesional.-Este apartado se valora hasta un máximo de 35 puntos sobre 100, teniendo en cuenta principalmente los siguientes méritos. 2.2.A Formación académica. Se valora la calificación de la tesis, la mención de Doctorado europeo y la mención de calidad del programa de Doctorado. Las becas pre y postDoctorales obtenidas en convocatorias competitivas. Se consideran también los cursos y seminarios de especialización de su ámbito disciplinar así como la posesión de otros títulos. 2.2.B Se valoran las estancias pre y postDoctorales de carácter investigador y/o de formación atendiendo a su duración, a la calidad del programa y de la institución receptora. 2.2.C Experiencia docente. Se valoran la amplitud, intensidad y tipo de la docencia en su ámbito disciplinar universitario en enseñanzas regladas y no regladas. Las evaluaciones que sobre la calidad de su docencia aporte el solicitante. La participación en proyectos de innovación docente, en planes y equipos de trabajo relacionados con el Espacio Europeo de Educación Superior. La participación en cursos, seminarios y congresos específicamente orientados a la formación teórico-práctica para la actividad docente. La elaboración de material docente y las publicaciones relacionadas con la docencia. 2.2.D Experiencia profesional. Se valora la duración y la responsabilidad ejercida en empresas o instituciones, y su relación con la labor como profesor Ayudante Doctor. 2.3 Otros méritos.-Este apartado se valora hasta un máximo de 5 puntos sobre 100. Se valoran el expediente académico de la titulación principal, las becas de iniciación y de colaboración a la investigación, así como cualquier otro mérito no valorado en los restantes criterios. 
M. ${ }^{\mathrm{a}}$ Fernanda Moretón Sanz




SELECCIÓN, EVALUACIÓN Y ACREDITACIÓN DEL PROFESORADO...

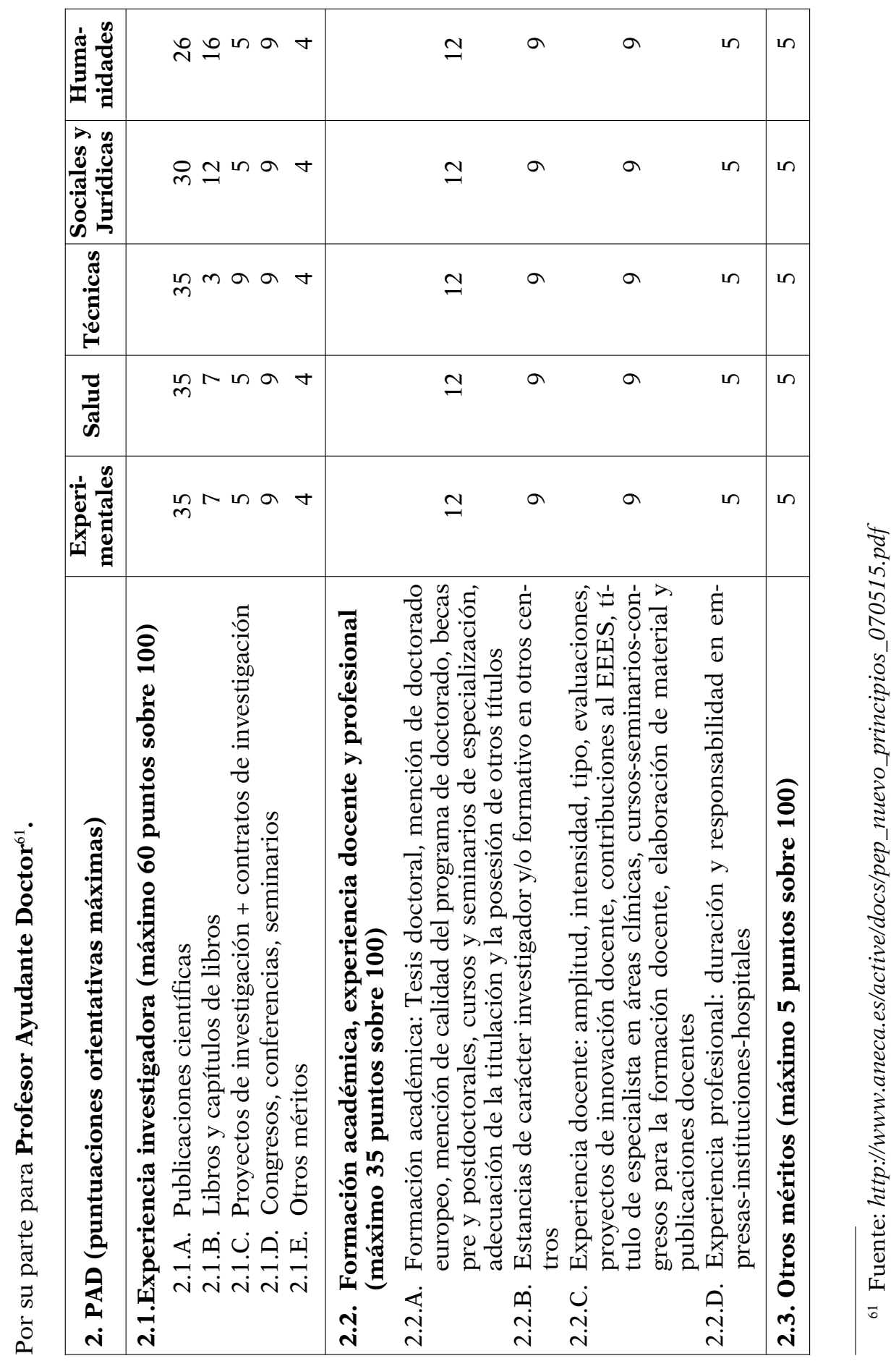




\section{V.4. Notas sobre el derecho a la evaluación y reconocimiento de sexenios de investigación del profesorado contratado: la UNED y el convenio de colaboración con la CNEAI}

Con la aprobación de la LO 6/2001, de 21 de diciembre, de Universidades, se pone término a la singular figura del contratado administrativo y, por fin, se ajusta el sistema y régimen jurídico del profesorado no funcionario a la del Derecho del Trabajo $^{62}$. En definitiva y pese a que fuese una cuestión sobrevenida en trámite de enmiendas, se produce —en los albores del XXIla laboralización del profesorado contratado, con directas consecuencias en materia de negociación colectiva donde nada impide que se incluya en los convenios el derecho a la evaluación de sus méritos específicos.

A estos extremos y para la finalidad pretendida en este trabajo, se añade que la investigación es un derecho y un deber del profesorado. Por su parte, la reforma operada sobre la LO 6/2001 por la LO 4/2007, de 12 de abril, añade el art 40.1 bis que advierte que «la Universidad apoyará y promoverá la dedicación a la investigación de la totalidad del Personal Docente e Investigador Permanente», mencionándose también de forma expresa que la evaluación de la actividad y dedicación investigadora y la contribución al desarrollo científico, tecnológico o artístico, será criterio relevante para determinar su eficiencia en su actividad profesional.

Además de la destacada laboralización del profesorado contratado y del reconocimiento de la plena capacidad docente e investigadora del contratado doctor (o figura asimilable), se incorpora otra novedad como es la posibilidad de que su actividad investigadora sea evaluada en idénticas condiciones y por idénticos méritos y bases que la del profesorado funcionario.

En el supuesto de la UNED en 2007 se suscribe convenio específico de colaboración con la CNEAI, destinado a que los laborales permanentes puedan ejercitar su derecho a la evaluación de su actividad investigadora. Prorrogado en 2008, este trabajo se dirige a los resultados y consecuencias de estas convocatorias ${ }^{63}$.

62 En este sentido, vid., de la autora de estas líneas la comunicación presentada y evaluada positivamente por el Comité científico del VI Foro sobre la Evaluación de la Calidad de la Educación Superior y la Investigación.

${ }^{63}$ El artículo 23 del Real Decreto 50/2004, de 19 de enero, por el que se regula el régimen del profesorado contratado de a UNED, ya establecía las Retribuciones adicionales por méritos docentes, de investigación y de gestión: «1. Dentro de los lí- 


\section{REFLEXIONES CONCLUSIVAS}

Tras la indeterminación de la LRU del 83, el legislador de 2001 incorpora la mención a las áreas de conocimiento referidas a las relaciones de puestos de trabajo de profesorado funcionario y concreta que la competencia para la aprobación del Catálogo corresponde al Gobierno.

En cuanto a la reforma de la LOU de 2001, se altera el sistema de acceso que pasa de la habilitación a la acreditación nacional para profesorado funcionario. Y en este sentido, se ha de advertir que las menciones al área de conocimiento se concretan, exclusivamente en aquellos preceptos que han mantenido su redacción de 2001 referidas en singular a plazas de profesorado al Personal de cuerpos de funcionarios docentes universitarios que ocupen plaza vinculada a servicios asistenciales de instituciones sanitarias. Así declara el artículo 61 que «El personal de los cuerpos de funcionarios docentes univer-

mites y de acuerdo con los criterios y procedimientos que se establezcan al efecto en materia de personal laboral del sector público estatal y con cargo a lo previsto a favor de la UNED en las leyes anuales que aprueben los Presupuestos Generales del Estado, el Ministerio de Educación, Cultura y Deporte podrá acordar con carácter anual el establecimiento de una partida destinada a la asignación de retribuciones adicionales por méritos docentes, de investigación y de gestión para el personal docente e investigador contratado laboral perteneciente a las figuras contractuales de profesor ayudante doctor, profesor colaborador y profesor contratado doctor. 2. La asignación de las retribuciones adicionales a las que se refiere este artículo deberá tener en cuenta, entre otros criterios, la singular dedicación y experiencia docente e investigadora, la especial trayectoria académica, el reconocimiento a la productividad investigadora, premios extraordinarios de doctorado o premios de investigación de especial significación, así como méritos de especial dedicación a la gestión universitaria. 3. Las solicitudes de asignación serán presentadas, a título individual, ante el Consejo de Gobierno de la universidad por el personal docente e investigador contratado mencionado en el apartado 1 y deberán acompañar la previa valoración realizada por la Agencia Nacional de Evaluación de la Calidad y Acreditación de los méritos alegados. 4. Mediante resolución del Director General de Universidades, se establecerá, el procedimiento aplicable, los criterios de valoración de méritos y los modelos de solicitud que deberán ser presentados. 5. Una vez examinadas las solicitudes, el Consejo de Gobierno podrá proponer al Consejo Social la asignación de tales retribuciones adicionales, con carácter singular e individualizado, para dicho personal docente e investigador. 6 . La retribución adicional es personal, no consolidable y de carácter variable, que se concede a solicitud del interesado, y tendrá un único componente en el que se contemplará la concurrencia de méritos docentes, de investigación y de gestión, compatibles con la figura de personal docente e investigador de que se trate y referidos al curso del ejercicio o a cursos anteriores. La retribución adicional se abonará anualmente, de una sola vez, o por mensualidades. Su percepción no supondrá ningún derecho individual respecto de las valoraciones o apreciaciones correspondientes a las evaluaciones de periodos sucesivos. 7. La UNED hará pública la relación de las cantidades asignadas individualmente en concepto de retribución adicional». 
sitarios que ocupen una plaza vinculada a los servicios asistenciales de instituciones sanitarias, en áreas de conocimiento de carácter clínico asistencial»; o en idéntico sentido en el artículo 62.

Como, por otra parte, no se ha modificado el tenor del artículo 71, la noción de área pervive aplicada específicamente al sistema del profesorado funcionarial y referida la competencia para la elaboración del Catálogo al Consejo «Artículo 71. Áreas de conocimiento. 1. Las denominaciones de las plazas de la relación de puestos de trabajo de profesores funcionarios de cuerpos docentes universitarios corresponderán a las de las áreas de conocimiento existentes. A tales efectos, se entenderá por área de conocimiento aquellos campos del saber caracterizados por la homogeneidad de su objeto de conocimiento, una común tradición histórica y la existencia de comunidades de profesores e investigadores, nacionales o internacionales. 2. El Gobierno establecerá y, en su caso, revisará el catálogo de áreas de conocimiento, previo informe del Consejo de Coordinación Universitaria [ahora en los términos vistos se refiere al Consejo de Universidades]».

Por su parte y como he destacado en otro lugar resulta conveniente recordar la escasa aspiración de la Universidad por atender a las evidencias prácticas que parece que quieren cohonestar las plantillas actuales, que quizás por razones de política estén sobredimensionadas, con la dinamización de las materias y contenidos de las nuevas disciplinas.

El problema de fondo que se plantea es la definición de la plantilla docente y de la carga docente, criterios ambos utilizados de forma preferente para la dotación económica de la convocatoria de plazas, de modo que ahora la batalla se traslada a la asunción de docencia en los nuevos planes de grados empeñadas ciertas disciplinas en acaparar asignaturas que con más o menos justificación se aproximen a su área de conocimiento con la intención así de conservar la posibilidad de promoción en la pirámide funcionarial y la contratación de profesorado en régimen laboral. La duda es que si con ello se consigue la finalidad pretendida por el EEES.

Repárese en que en el sistema se da prioridad absoluta a la investigación -en la que prima la absoluta libertad de elección y manifestación-, frente a la docencia que se constriñe a las necesidades del servicio.

Finalmente y como se ha dicho, no resultaría extraño que buena parte del profesorado contratado en régimen laboral con carácter indefinido, prefiriese seguir en esta categoría. La justifi- 
cación a esta intuitiva afirmación se basa no tanto en las dificultades de la acreditación toda vez que a mi juicio los criterios están definidos y pese a que su aplicación pueda ser discutible, ha clarificado qué es lo que se exige del profesorado y, a mayor abundamiento, ratifican los reclamados para la evaluación del profesorado contratado doctor, por lo que no resultará difícil para quien haya superado esta evaluación y haya seguido en la misma línea de proyección investigadora, docente y de gestión, conseguir la acreditación.

La justificación, digo, se puede encontrar en los puntos críticos de la ANECA y el programa Docentia: a) Lentitud en la tramitación, se apuran los seis meses desde la petición hasta la contestación; b) Tramitación interna de la plaza de promoción en el Departamento; c) Ratificación en cualquiera de las dos convocatorias anuales de Comisiones de Ordenación para plazas; d) Demora en la publicación en el BOE; e) Celebración de la plaza. En resumidas cuentas desde quien haya migrado sus datos curriculares de la aplicación de contratados a la de funcionarios, añada sus nuevos méritos y ratifique su solicitud, hasta que adquiera la condición de funcionario bien pueden pasar casi dos años.

Teniendo en cuenta que la laboralización ha implicado el refuerzo y el peso específico del profesorado contratado al amparo del Estatuto de Trabajadores y su complementación con los convenios respectivos, no es insólito pensar que quien obtiene identidad salarial y equiparación de complementos no desee pasar por un trance largo y despacioso, por innecesario, como es el sistema de concursos que en singular y al día de hoy rigen en la UNED para los TU. 